\title{
Cytochromes c in Archaea: distribution, maturation, cell architecture, and the special case of Ignicoccus hospitalis
}

\section{OPEN ACCESS}

Edited by:

Sonja-Verena Albers,

University of Freiburg, Germany

Reviewed by:

Ulrike Kappler,

University of Queensland, Australia

Christiane Dahl,

Rheinische

Friedrich-Wilhelms-Universität Bonn,

Germany

*Correspondence: Arnulf Kletzin

Department of Biology, Sulfur

Biochemistry and Microbial

Bioenergetics, Technische Universität Darmstadt, Schnittspahnstraße 10,

64287 Darmstadt, Germany

Kletzin@bio.tu-darmstadt.de

tPresent Address:

Thomas Heimerl,

LOEWE Research Center for Synthetic

Microbiology (SYNMIKRO), Philipps

University of Marburg, Marburg,

Germany

Specialty section:

This article was submitted to Microbial Physiology and Metabolism,

a section of the journal

Frontiers in Microbiology

Received: 12 January 2015

Accepted: 23 April 2015

Published: 12 May 2015

Citation:

Kletzin A, Heimerl T, Flechsler J, van Niftrik L, Rachel $R$ and Klingl A (2015) Cytochromes c in Archaea: distribution, maturation, cell architecture, and the special case of Ignicoccus hospitalis.

Front. Microbiol. 6:439. doi: 10.3389/fmicb.2015.00439

\section{Arnulf Kletzin ${ }^{1 *}$, Thomas Heimerl ${ }^{2 \dagger}$, Jennifer Flechsler ${ }^{2}$, Laura van Niftrik ${ }^{3}$, Reinhard Rachel ${ }^{2}$ and Andreas Klingl ${ }^{4}$}

\begin{abstract}
'Department of Biology, Sulfur Biochemistry and Microbial Bioenergetics, Technische Universität Darmstadt, Darmstadt, Germany, ${ }^{2}$ Fakultät für Biologie und Vorklinische Medizin, Zentrum für Elektronenmikroskopie, Universität Regensburg, Regensburg, Germany, ${ }^{3}$ Department of Microbiology, Institute for Water and Wetland Research, Radboud University Nijmegen, Nijmegen, Netherlands, ${ }^{4}$ Department of Biology I, Plant Development, Biocenter LMU Munich,

Planegg-Martinsried, Germany
\end{abstract}

Cytochromes c (Cytc) are widespread electron transfer proteins and important enzymes in the global nitrogen and sulfur cycles. The distribution of Cytc in more than 300 archaeal proteomes deduced from sequence was analyzed with computational methods including pattern and similarity searches, secondary and tertiary structure prediction. Two hundred and fifty-eight predicted Cytc (with single, double, or multiple heme $c$ attachment sites) were found in some but not all species of the Desulfurococcales, Thermoproteales, Archaeoglobales, Methanosarcinales, Halobacteriales, and in two single-cell genome sequences of the Thermoplasmatales, all of them Cren- or Euryarchaeota. Other archaeal phyla including the Thaumarchaeota are so far free of these proteins. The archaeal Cytc sequences were bundled into 54 clusters of mutual similarity, some of which were specific for Archaea while others had homologs in the Bacteria. The cytochrome $c$ maturation system I (CCM) was the only one found. The highest number and variability of Cytc were present in those species with known or predicted metal oxidation and/or reduction capabilities. Paradoxical findings were made in the haloarchaea: several Cytc had been purified biochemically but corresponding proteins were not found in the proteomes. The results are discussed with emphasis on cell morphologies and envelopes and especially for double-membraned Archaea-like Ignicoccus hospitalis. A comparison is made with compartmentalized bacteria such as the Planctomycetes of the Anammox group with a focus on the putative localization and roles of the Cytc and other electron transport proteins.

Keywords: cytochrome c, Archaea, Ignicoccus hospitalis, ANME, anammox planctomycetes, bioinformatics, molecular modeling

\section{Introduction}

The chemolithotrophic, hyperthermophilic Archaeon Ignicoccus hospitalis is unusual in several aspects (Huber et al., 2012). First, it is the only host of the symbiotic and/or parasitic Archaeon Nanoarchaeum equitans. Second, I. hospitalis cells do not possess a cell wall. Instead they comprise 

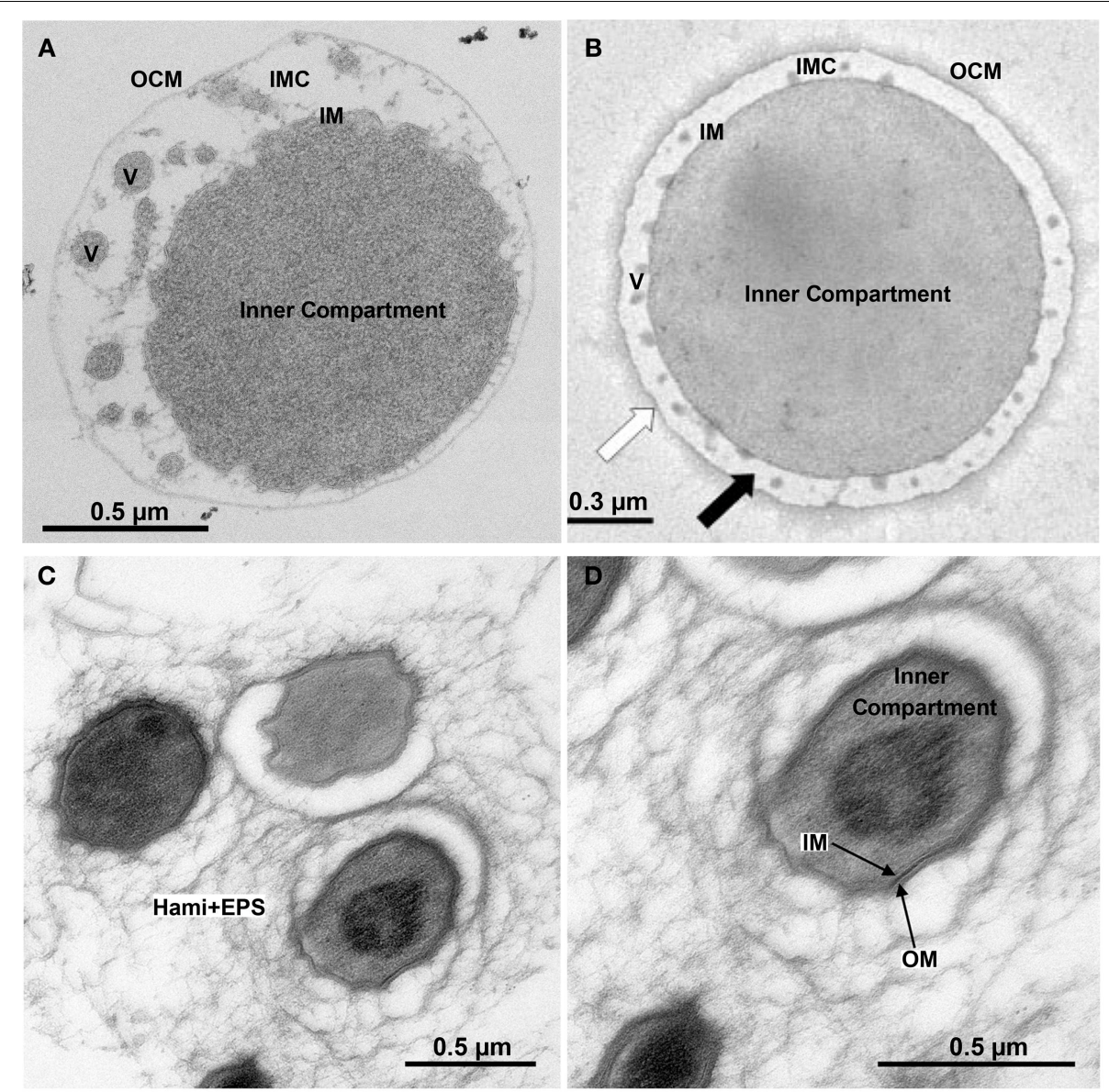

FIGURE 1 | Ultrastructure of double-membraned Archaea.

Transmission electron micrographs of ultrathin sections of high-pressure frozen, Epon-embedded cells; (A) Ignicoccus hospitalis; (B)

Methanomassiliicoccus luminyensis taken and modified from Dridi et al.

(2012), with permission from the International Journal of Systematic and
Evolutionary Microbiology, confirmation number 11261287; (C,D)

Candidatus "Altiarchaeum hamiconexum." Abbreviations and explanation: IMC, intermembrane compartment; IM, inner membrane; OCM, outer cellular membrane; V, vesicles; EPS, extracellular polymeric substances; Hami, extracellular long hooked pili (Moissl et al., 2005). two membrane systems: an inner membrane (IM) encompassing the densely contrasted inner compartment, which contains DNA, ribosomes, and presumably many biosynthetic enzymes (Figure 1; Huber et al., 2012). The outer cellular membrane (OCM) surrounds the cell and contains regularly arrayed small hydrophobic proteins (Burghardt et al., 2007; Huber et al., 2012). A lightly contrasted intermembrane compartment separates both membranes (IMC, $50-1000 \mathrm{~nm}$ in width). The IMC contains densely contrasted tubes and vesicles directly involved in the interplay between both membranes (Huber et al., 2012; Meyer et al., 2014). The energy-converting enzymes ATP synthase, hydrogenase, sulfur reductase, and acetyl-CoA synthase are located in the OCM representing the cellular and bioenergetic boundary of the cell from the non-living environment (Küper et al., 2010; Mayer et al., 2012). Therefore, the OCM of I. hospitalis is not equivalent to the outer membrane of Gram-negative bacteria (Huber et al., 2012).

The coloration of $I$. hospitalis cells is a third unusual aspect: soluble extracts and membrane fractions are brightly red resulting from a high content of soluble and membrane-bound cytochromes $c$ (Cytc). We had purified three different Cytc from I. hospitalis cells, however, we can so far only speculate about their in vivo function (Naß et al., 2014). Two of these proteins, named Igni_0955 and Igni_1359 after their GenBank locus tag numbers, were present in soluble and membrane extracts, while the third one (Igni_0530) was present only in the membrane fractions.

Cytochromes $c$ are widely distributed in the living world. For example, Pseudomonas, Paracoccus, and Thermus species possess the genes for the canonical mitochondrial-type respiratory chain including the $b c_{1}$ complex (complex III) and the soluble monoheme Cytc as electron carrier between complexes III and IV (reviewed, for example, in Mooser et al., 2006; Noor and Soulimane, 2013). Among Archaea, the bioenergetics and the composition of electron transport chains was most thoroughly studied in Pyrococcus/Thermococcus spp., methanogens, haloarchaea, and Sulfolobales (Schäfer et al., 1999; Schäfer, 2004; Thauer et al., 2008; Mayer and Müller, 2014). Among these, only those methanogens of the Methanosarcinales order 
possess Cytc, whereas they were not detectable-biochemically or by sequence comparisons-in the other taxa or in other methanogens (Thauer et al., 2008).

The hallmark of Cytc is a covalent ligation of a heme $b$ moiety to the protein backbone. In most cases, two cysteine side chains-usually present in a sequence motif $\mathrm{CxxCH}$-form thioether linkages to the heme backbone. The histidine provides the proximal axial ligand of the octahedral coordination sphere of the iron in the center of the heme. The distal axial ligand comes from a distant His, Met or, less frequently, other residues. Variations of this theme may involve penta- instead of hexacoordinated hemes as for example in Cytc', a CxxCK hemebinding motif (e.g., in nitrite reductases; Lockwood et al., 2011) or different spacing of the cysteine residues (Kern et al., 2011). Motif variations usually occur in multiheme cytochromes $c$ (MCC) acting as enzymes and not as electron transfer proteins.

The double thioether linkage is formed by maturation proteins, which are grouped by phylogenetic and functional relationship into five systems (Allen et al., 2006; Allen, 2011; de Vitry, 2011; Simon and Hederstedt, 2011; Stevens et al., 2011). In most bacteria, Cytc maturation (CCM) takes place on the positive (p) side of the cytoplasmic membrane (maturation systems I and II; Simon and Hederstedt, 2011; Stevens et al., 2011). The apoproteins are transported across the cytoplasmic membrane by the General Secretory Pathway (GSP) (Sec-System) so that they carry a recognizable signal sequence at their $\mathrm{N}$ termini, which is-apart from the $\mathrm{CxxCH}$ motif-the second feature important for bioinformatic prediction of these proteins. System I or CCM (Cytc maturation) consists of up to nine different proteins including a heme ligase, chaperones, ATPtransporters, and protein disulfide isomerases (Stevens et al., 2011; Verissimo and Daldal, 2014). It occurs in Alpha- and other Gammaproteobacteria and it was identified in Archaea during a previous study (Allen et al., 2006). System II consists of less and mostly unrelated proteins compared to System I (Simon and Hederstedt, 2011).

The number of studies conducted about occurrence and function of Cytc in Archaea is limited and no systematic survey was so far performed. Apart from I. hospitalis (Naß et al., 2014), Cytc were found biochemically in the hydrogen-oxidizing and sulfur-reducing complex of the related Archaea Pyrodictium abyssi and P. brockii (Pihl et al., 1992; Dirmeier et al., 1998), in a $b c_{1}$ complex from the likewise related microaerophilic Aeropyrum pernix (Kabashima and Sakamoto, 2011), in the nitrate reducer Pyrobaculum aerophilum (Feinberg and Holden, 2006; all of them hyperthermophilic Crenarchaeota), in cultured (Methanosarcina spp.) and uncultured species (ANME-1 and ANME-2) of the Methanosarcinales and in several haloarchaea (all Euryarchaeota; Kamlage and Blaut, 1992; Scharf et al., 1997; Sreeramulu et al., 1998; Sreeramulu, 2003; Meyerdierks et al., 2010; Wang et al., 2011, 2014). Surprisingly, experimental gene identification was accomplished only for a few of these species including the three multiheme Cytc from I. hospitalis and of the $b c_{1}$ complex of the related A. pernix (Kabashima and Sakamoto, 2011; Naß et al., 2014).

When looking at $I$. hospitalis and trying to put the pieces of this puzzle together, questions arise about the distribution of Cytc in different types of archaeal cells, about their targeting and about the nature and location of the biogenesis system. Since occurrence and distribution of Cytc in Archaea was not recently analyzed in detail, we present here the results of a systematic computational survey. The results are discussed with respect to cell ultrastructure and the physiology of the different archaeal with a special focus on the comparison of $I$. hospitalis with other single, double, and triple-membraned Archaea and Bacteria.

\section{Materials and Methods}

\section{Bioinformatic Procedures}

The complete non-redundant set of archaeal proteins was downloaded July 23rd, 2014 from Uniprot database in FASTA format (http://www.uniprot.org/). In addition, archaeal sequences deposited at GenBank in 2014 were downloaded Janurary 6th, 2015, from the non-redundant protein database (NR). Both sets of sequences were curated for duplicate species and combined. The total set of 883,607 proteins (Table 1) were analyzed in installments of up to 30,000 sequences for the amino acid pattern $\mathrm{CxxCH}$ using the 3 of5 algorithm (Seiler et al., 2006) installed locally at the HUSAR Sequence Analysis Facility at the German Cancer Research Center, Heidelberg (http:// genius.embnet.dkfz-heidelberg.de/menu/w2h/w2hdkfz/; 3 of5 web server available at http://www.dkfz.de/mga2/3of5/3of5. html). The hits (Table 1) were converted into a tab-delimited list of accession numbers and corresponding hit motifs using the advanced "find and replace" features of Microsoft Word and finally inserted into a Microsoft Excel work sheet (Table S1). A list of database accession numbers (Uniprot identifiers and GenBank GI numbers) was generated from the appropriate Excel column and the full FASTA-formatted sequences were retrieved from the respective databases. They were also converted into a tab-delimited format and incorporated into the Excel table. Delimiters $(\S, \$, \#)$ were placed into additional columns for re-formatting purposes. For addition of the locus tags, the same set of sequences was retrieved in GenBank format, reformatted as above and copied into a separate work sheet. The column with the locus tags or gene designations was copied into the main table as appropriate.

The set of 4795 hit sequences was analyzed for transmembrane helices (TMH) using the TMHMM (one line per protein; http:// www.cbs.dtu.dk/services/TMHMM-2.0/; Krogh et al., 2001) and SOSUI batch servers (http://harrier.nagahama-i-bio.ac.jp/sosui/; Hirokawa et al., 1998). The results were reformatted and again copied to the main table (Table S1). Signal sequences were predicted using SignalP (http://www.cbs.dtu.dk/services/ SignalP/, model for Gram-negative bacteria; Petersen et al., 2011) and TatP (http://www.cbs.dtu.dk/services/TatP/; Bendtsen et al., 2005) for GSP and twin-arginine protein translocation (TAT) signal peptides, respectively. Proteins were also analyzed using OCTOPUS in cases of manually identified Cytc candidates with no result in the $\mathrm{N}$-terminal TMH prediction. Sequences with three or more $\mathrm{CxxCH}$ motifs were defined as multiheme Cytc (MCC) unless shown not to be-by a high similarity to known non-cytochrome proteins in BLASTP searches (e.g., RecJ homologs). Additionally, various known Cytc and MCCs were used to query the Archaea subsection of the GenBank protein database. Sequences with two or one $\mathrm{CxxCH}$ motif were 
TABLE 1 | Statistics of cytochrome c prediction in Archaea.

\begin{tabular}{|c|c|}
\hline Total No. of archaeal proteins & 888,023 \\
\hline Uniprot non-redundant proteins July 2014 & 816,158 \\
\hline Genbank additional archaeal proteins & 71,865 \\
\hline No. of defined species/genomes strains & 312 \\
\hline Total hits with $\mathrm{CxxCH}$ search & 4795 \\
\hline No. of duplicated sequence hits & 563 \\
\hline No. of unique sequences among duplicates & 222 \\
\hline Multiheme cytochrome $c$ candidate $\left(\mathrm{No}_{\mathrm{C} x \mathrm{CH}} \geq 3\right.$ per sequence) & 179 \\
\hline Same with N-term. $\mathrm{TMH}$ and/or predicted signal seq. & 159 \\
\hline No. of predicted multiheme cytochromes $c$ & 167 \\
\hline $\begin{array}{l}\text { No. of species/strains (cultured or uncultured) with multiheme } \\
\text { cytochromes c }\end{array}$ & 29 \\
\hline False positives (e.g., RecJ; 3x CxxCH each) & 12 \\
\hline No. of proteins with $2 \mathrm{CxxCH} /$ sequence & 206 \\
\hline Same with N-term.TMH and/or predicted signal/TAT seq. & 24 \\
\hline No. of predicted diheme cytochromes $c$ & 28 \\
\hline $\begin{array}{l}\text { No. of species (cultured or uncultured) with diheme } \\
\text { cytochromes c }\end{array}$ & 20 \\
\hline False positives & 178 \\
\hline No. of proteins with $1 \mathrm{CxxCH} /$ sequence & 4410 \\
\hline Same with N-term. TMH and/or predicted signal seq. & 157 \\
\hline No. of predicted monoheme cytochromes $c$ candidates & 64 \\
\hline $\begin{array}{l}\text { No. of species (cultured or uncultured) with monoheme } \\
\text { cytochromes c }\end{array}$ & 39 \\
\hline False positives & 4347 \\
\hline Total No. of proteins subjected to structure prediction & 1754 \\
\hline
\end{tabular}

No. of cytochrome $c$ candidates clustered for detailed analysis

350

\section{No. of predicted archaeal cytochrome $c$ proteins}

No. of sequence similarity clusters

258

54

No. of predicted archaeal Cytc in species with 3 or more $\mathrm{ccm}$ genes $^{a}$

No. of species/environmental samples

No. of predicted archaeal Cytc in species with $0-1 \mathrm{ccm}$ genes ${ }^{b}$

No. of species

\section{a See Figure 2a;}

${ }^{b}$ See Figure $\mathbf{2 b}$.

considered Cytc candidates if they contained an N-terminal $\mathrm{TMH}$ and/or a signal sequence. Candidates were subjected to three-dimensional modeling using the batch processing mode of the Phyre ${ }^{2}$ server (http://www.sbg.bio.ic.ac.uk/phyre2/html/ page.cgi?id=index; Kelley and Sternberg, 2009). The results were purged from non-significant models (i.e., low confidence and/or alignment coverage percentage) and significant hits were used to evaluate the previously defined Cytc candidate clusters for completeness and correct identification. The I. hospitalis Cytc were also modeled using the I-Tasser server with omission of the respective signal sequences (http://zhanglab.ccmb.med. umich.edu/I-TASSER/; Roy et al., 2010). The resulting Igni_0759 model was further adjusted by taking the predicted heme ligand out of the I-Tasser results files. The pdb coordinates including the heme were imported into UCSF Chimera (Pettersen et al., 2004) and the heme position was adjusted manually in order to build the thioether bonds between the heme and the two cysteine side chains followed by energy minimization. In the next round, a bond between the heme iron and the $\mathrm{N} \varepsilon$ atom of the proximal ligand $\mathrm{His}_{32}$ was created and the energy minimization step repeated. The figure was prepared in Pymol (Delano, 2002).

The set of 4795 primary hit sequences was converted into a BLAST database using the standalone BLAST+ program downloaded from NCBI (http://blast.ncbi.nlm.nih.gov/Blast.cgi? $\mathrm{CMD}=$ Web\&PAGE_TYPE=BlastDocs\&DOC_TYPE=Download). Cytc candidates were compared against this database in order to find missing homologs and to identify clusters of mutually similar Cytc candidates. Clusters were aligned separately (Supplementary Alignment File Archaea_Cytc.zip). The multiheme cytochromes identified by Sharma et al. (2010) were also downloaded in FASTA format, converted into a separate BLAST database; they were used for the determination of cluster similarity and to relate clusters defined in this study to those from Sharma et al. (2010; Table S1). The primary hit sequences were also compared using BLASTP against the conserved domain database (CDD) installed locally.

Our methods differed from previous computational studies presented by Bertini et al. (2006) and Sharma et al. (2010). Both used HMMs (Sharma et al. for diheme and multiheme Cytc prediction only) and both used comparison against the protein family database for curation (PFAM; http://pfam.xfam.org/). Many of the cytochromes predicted here are not even clustered in PFAM or in NCBI's CDD for lack of 3D structures and/or biochemical description (Table S1, CDD search) so that we used clustering combined with structure prediction in order to identify Cytc folds in proteins. The main advantages of the methods used here are simplicity and no need for specialized software. They can be repeated from almost any standard PC or Mac using internetavailable tools and free software (except for Microsoft Office products). The likewise freely accessible structure prediction part helped in assessing the previous conclusions.

The search for Cytc biosynthesis proteins was performed essentially as described (Allen et al., 2006). For system I, the $\mathrm{CcmB}, \mathrm{CcmC}, \mathrm{CcmE}, \mathrm{CcmF}$ proteins from Methanosarcina acetivorans, A. pernix, Haloarcula marismortui (for GI numbers, see Allen et al., 2006), and E. coli were used in BLASTP searches against the archaeal proteins. BLASTP searches were repeated with archaeal hit sequences because sequence similarities were often low between unrelated Archaea. The Leptospira interrogans $\mathrm{CcmH}$ (GI:45656703) was used in addition, as homologs had so far not previously been found in Archaea (Allen et al., 2006). For System II, Wolinella succinogenes ResB was used (GI:34484157); for System III, the two heme lyases from Saccharomyces cerevisiae were used and for System IV the Chlamydomonas reinhardtii CCB1-4 proteins (de Vitry, 2011).

\section{Electron Microscopy}

For electron microscopy analysis, fresh I. hospitalis cells were cultivated, high-pressure frozen and freeze-substituted in 95\% 
acetone, $0.5 \%$ glutaraldehyde, $0.5 \%$ uranyl acetate, and 5\% water as described (Rachel et al., 2010; Naß et al., 2014). After freeze-substitution fixation, samples were embedded in Epon. For localization of proteins on ultrathin sections, the primary antiserum directed against Igni_0955 was used without further purification. For detection, secondary antibodies coupled to ultra-small gold particles were made visible by silver enhancement. Images were recorded as described ( $\mathrm{Naß}$ et al., 2014). The Kuenenia stuttgartiensis cell had also been highpressure frozen, freeze-substituted in acetone containing $2 \%$ $\mathrm{OsO}_{4}, 0.2 \%$ uranyl acetate, and $1 \%$ water and Epon-embedded as described (Wu et al., 2012). Candidatus "Altiarchaeum hamiconexum" cells were sampled and prepared for electron microscopy as described elsewhere (Perras et al., 2014; Probst et al., 2014a).

\section{Results}

\section{Prediction of Cytochromes $c$ and their Maturation Proteins in Archaea}

Motif and similarity searches and homology modeling were applied to the prediction of Cytc and their distribution in Archaea. 4795 archaeal proteins (Table 1) were found to contain at least one $\mathrm{CxxCH}$ amino acid pattern (Table S1). One hundred and seventy nine proteins contained at least three $\mathrm{CxxCH}$ motifs (defined here as MCCs), among those, 159 had a recognizable signal sequence and/or a predicted transmembrane helix (TMH) at their N-termini (Table 1). 12 sequences with three $\mathrm{CxxCH}$ motifs each were identified with BLASTP searches as RecJ exonuclease homologs and were considered as false positives. RecJ family proteins with $1-3 \mathrm{CxxCH}$ motifs were among the most common random hits in the motif searches. The remaining 167 proteins from 29 archaeal species/strains were considered as multiheme cytochromes $c$ (MCC; Table 1 and Table S1).

The prediction of di- and mono-heme Cytc from the motif search resulted in a higher proportion of non-specific hits. Twenty eight out of 206 proteins from 20 species were identified as diheme Cytc candidates (Tables S1, S2). The majority of 4410 proteins with a single $\mathrm{CxxCH}$ motif (Table 1) were random hits with no recognizable similarity to Cytc or any feature suggestive of them being one. Among the 229 proteins with an $\mathrm{N}$-terminal TMH and/or signal sequence, only those were considered as Cytc candidates if they were either similar to known Cytc sequences (e.g., cluster 30, homologs of the A. pernix $b c_{1}$ complex), or if the $\mathrm{CxxCH}$ motif was conserved in a significant percentage of the homologs found in BLAST searches, and if the proteins were not bona fide members of other known protein families. Thioredoxin family proteins (including protein disulfide isomerases) were frequently occurring false positives with an N-terminal $\mathrm{TMH}$; subunits of RNA and DNA polymerases, molybdopterin biosynthesis proteins, endonucleases, $\mathrm{Zn}^{2+}$-binding domains, and iron-sulfur proteins were among the most frequent false positives without a TMH.

One thousand seven hundred and fifty four proteins annotated as "hypotheticals" were subjected to batch structure prediction. The fold recognition often gave necessary hints for the decision whether a protein or a cluster represents Cytc. No further Cytc candidates were spotted in this subset of the data. After reducing the score to 154 monoheme Cytc candidates falling into 30 similarity clusters (Tables S1, S2), 3D structure prediction was performed showing that 9 clusters all gave $\geq$ $96 \%$ confidence predictions with various Cytc, the prediction results of cluster 47 were considered of intermediate quality $(90 \%$ confidence). This and cluster 38 were included in the Cytc group. Seventeen sequence clusters were excluded from the Cytc group mostly because they gave significant modeling results with known non-Cytc proteins.

\section{Multiheme Cytochromes $c$ in Archaea}

With one exception (Figure 2), the presence of MCCs-encoding genes was restricted to four of the major archaeal orders: the Desulfurococcales, the genus Pyrobaculum within the order of the Thermoproteales (both Crenarchaeota), the Archaeoglobales, and the Methanosarcinales including the methane-oxidizing environmental candidate species of the ANME-1 and ANME-2 groups (Figures 2, 3). The highest numbers of predicted MCC were found encoded in those species known or suspected to thrive anaerobically by iron respiration like $F$. placidus and in the uncultured methane-oxidizing Archaea of the ANME-1 and ANME-2 groups. The maximal number of $\mathrm{CxxCH}$ motifs in a single sequence was 33 in a large protein from the euryarchaeote Ferroglobus placidus (Figure 2).

The predicted MCCs were grouped in 34 clusters according to sequence similarity (Tables S1, S2, multiple alignments in the compressed supplemental sequence file Archaea_Cytc.zip). Some of the archaeal MCCs belong to well-known families like the hydroxylamine oxidoreductases (sequence cluster No. 4; 11 hits), octaheme tetrathionate reductases (cluster No. 5; 7 hits), or the periplasmic nitrite reductases (No. 69; 3 hits). In contrast, the protein function of most of the MCCs from Archaea is not known; many do not even have bacterial counterparts (e.g., clusters 1, 2, 11, 12 etc.; Table S2). Sometimes, structure prediction of MCC candidate proteins gave high-confidence (100\%), full-length predictions. For example, protein models of cluster 1 matched with Thioalkalivibrio nitratireducens octaheme nitrite reductase (PDB accession 3f29) despite undetectably low sequence similarity, so that their function might nevertheless be inferred. Proteins of cluster 2 matched structurally octaheme tetrathionate reductases (PDB 1sp3; cluster 5). Other clusters gave more ambiguous results, which must be handled with care (Table S2), especially, when the number of $\mathrm{CxxCH}$ motifs in models and templates differed (e.g., clusters 8 and 9; not shown).

\section{Di- and Mono-heme Cytochromes c}

Among the predicted diheme Cytc (seven similarity clusters; Table S2 and (Supplementary File Archaea_Cytc.zip) were peroxidases of the MauG type (cluster 29), thiosulfate dehydrogenases (TDH; cluster 28), a $b c_{1}$ complex homolog from hyperthermophile Pyrolobus fumarii (cluster 30; the homologs from three other Desulfurococcales species have only one $\mathrm{CxxCH}$ motif including the biochemically characterized APE_1719 from A. pernix; Kabashima and Sakamoto, 2011), 


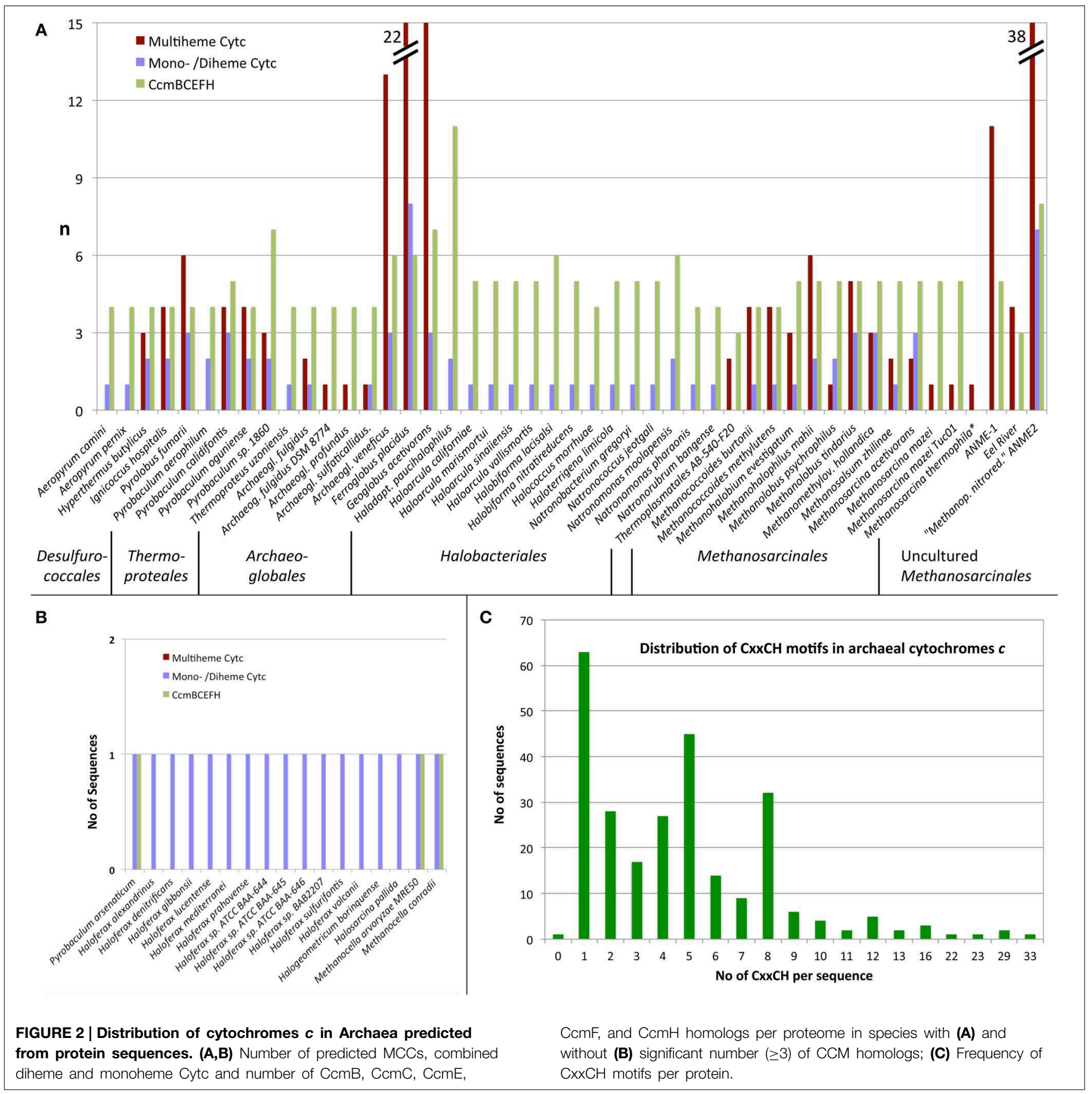

and Split-Soret Cytc (cluster 21), the latter with predicted Twin-Arginine signal peptides. Six of these proteins were from Archaeoglobales, two from the crenarchaeote Pyrolobus fumarii, four from Methanosarcinales while the remaining 16 proteins were from various haloarchaea, which do not harbor MCCs as far as we know (Figure 2).

Structure prediction of the MauG peroxidases, the $b c_{1}$ complex homologs and the Split-Soret Cytc were consistent with the templates and they covered $\geq 70 \%$ of the respective proteins with $100 \%$ confidence (Table S2). More interesting was the case of the TDH homologs (cluster 28): modeling suggested structural similarity to SoxA proteins, which catalyze, together with SoxX, the oxidative transfer of thiosulfate to a cysteine side chain of SoxYZ. Sequence similarity between these two sulfur cycle enzymes is low but modeling showed structural similarity. These archaeal TDH homologs are encoded in genomes of five haloarchaeal species in operon-like arrangements with genes for CCM proteins.

Sharma et al. (2010) had predicted MCCs (with 2 hemes/per protein or more instead of at least 3 hemes used here) in 8 


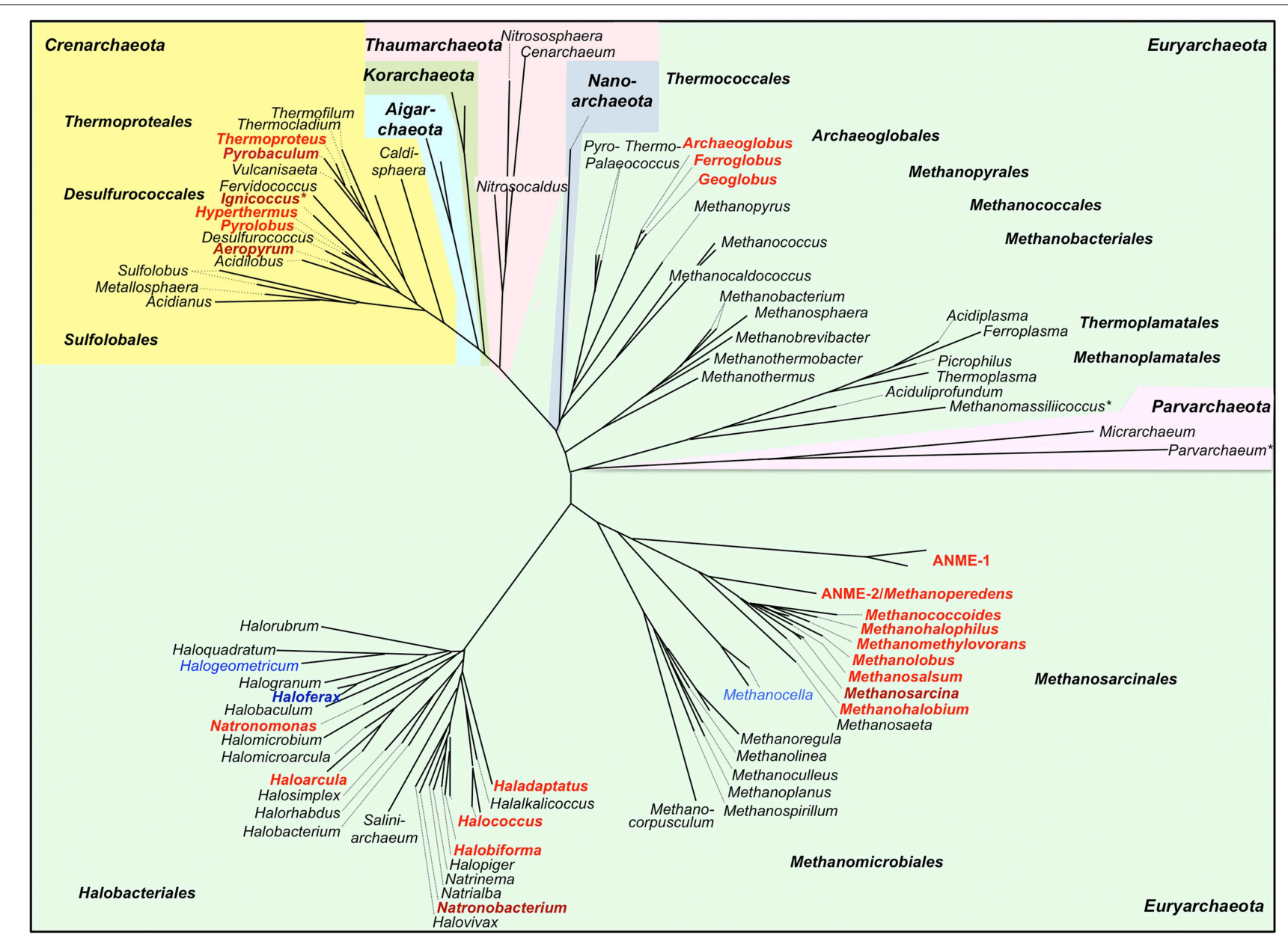

FIGURE 3 | Phylogenetic 16S rDNA dendrogram of the Archaea and distribution of predicted cytochrome $\boldsymbol{c}$ genes. The dendrogram was made from a $16 \mathrm{~S}$ alignment both calculated with MAFFT (Katoh and Standley, 2014; http://mafft.cbrc.jp/alignment/server/). Dark red/dark blue, Cytc biochemically found; red, Cytc-encoding and ccm genes found

(Figure 2A); blue, Cytc candidate genes but no or single ccm genes found
(Figure 2B); *Archaea with double membranes. Note: This dendrogram was created to depict the distribution of Cytc in Archaea and is based on 16S sequences only. The branching order of archaeal phyla does not correlate with more advanced dendrograms based on concatenated proteins sets. For a discussion of large-scale archaeal phylogeny, see for example Guy and Ettema (2011); Forterre (2013), and Petitjean et al. (2014). out of 47 then-available archaeal genome sequences. We found all of those with the methods used in this study, however our interpretation was sometimes different. For example, they had identified Methanospirillum hungatei Mhun_1396 and its paralog Mhun_1882 as putative diheme Cytc. The proteins are highly conserved in methanogens but the $\mathrm{CxxCH}$ motifs are not so that we disregarded these two candidates. We also identified many previously unrecognized MCCs annotated as hypotheticals in genome sequences.

Sixty four proteins were assigned as monoheme Cytc candidates from 12 sequence clusters (Table 1 and Table S1). The modeling approach gave results with templates like cytochrome $c_{(2)}$, cytochrome P460, SoxX, and Cytc subunits of NO reductase (NorC) or ethylbenzene dehydrogenase (Table S2). A special case is the nitrite reductase subunit Pars_0592 from Pyrobaculum arsenaticum, which was identified with BLASTP searches and which is similar to its heme-c containing homologs (68 and
$52 \%$ identity to the two $P$. aerophilum proteins PAE3598 and PAE1347, respectively) but which has a tyrosine residue instead of the first cysteine in the classical $\mathrm{CxxCH}$ motif. We suspect that there might be single or no covalent heme ligation in an otherwise functional protein.

\section{Cytochrome $c$ Maturation Proteins}

Cytochromes $c$ require maturation by heme ligases and, in most cases, transport proteins for the transfer of the heme moiety across the membrane to the electrochemically positive side. Cytochrome $c$ maturation system I (CCM) originally described from $E$. coli is one the two most common and the most complex CCM machinery of five known systems. The search for CCM proteins encoded in archaeal genomes was mainly done with sequence comparisons using BLAST and the $\mathrm{CcmB}, \mathrm{C}, \mathrm{E}, \mathrm{F}$, and $\mathrm{H}$ proteins as described by Allen et al. (2006) and in the Materials and Methods Section. The I. hospitalis genome encodes 

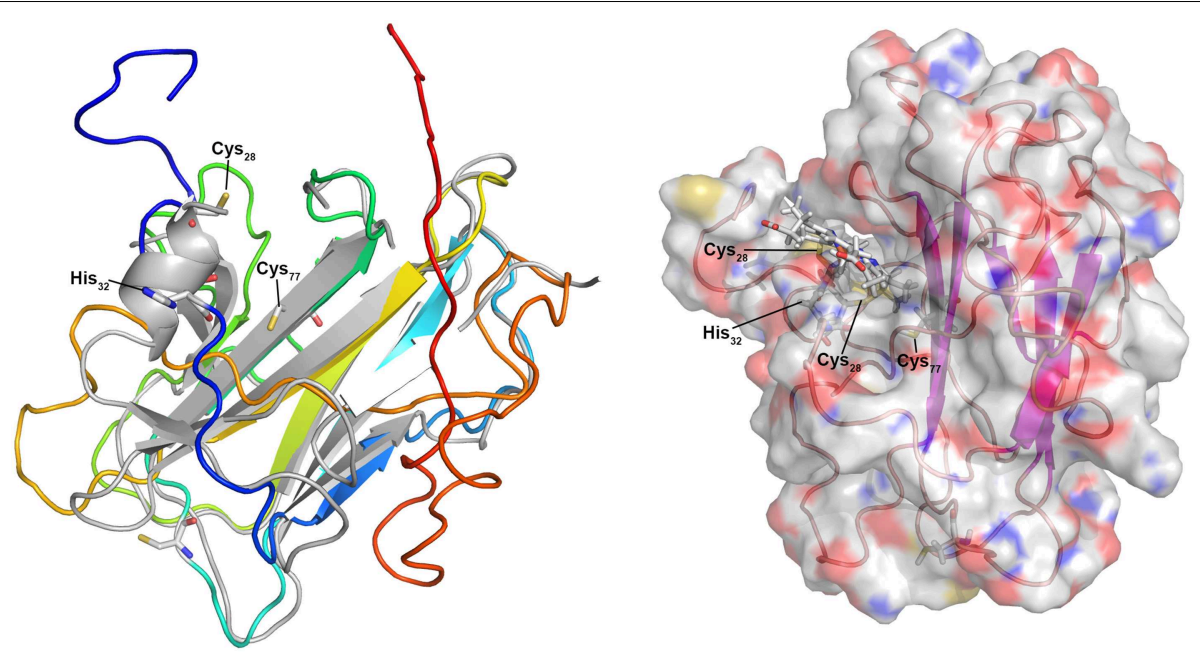

FIGURE 4 |3D model of the predicted monoheme cytochrome c Igni_0759 from I. hospitalis. Left panel: 3D model created using the I-Tasser server (Roy et al., 2010; rainbow color, $\mathrm{N}$-terminus blue) and superimposed over the modeling template (heparin-binding reelin- $\mathrm{N}$ domain of $\mathrm{f}$-spondin; PDB accession 3COO; Tan et al., 2008); Right panel: Igni_0759 3D model with heme $c$ connected to $\mathrm{Cys}_{28}$ and $\mathrm{Cys}_{31}$ side chains with the iron connected to $\mathrm{His}_{32}$. four proteins, $\mathrm{CcmB}, \mathrm{CcmC}, \mathrm{CcmE}$, and $\mathrm{CcmF}$ indicative of the presence of the entire CCM system. $\mathrm{CcmH}$ homologs were solely found in Ferroglobus placidus, while the remaining four proteins had homologs in 45 archaeal species, in which Cytc proteins were also predicted (Figure 2). Proteins of cytochrome maturation systems II-V were not identified in Archaea. It can be concluded from these results that the Cytc apoproteins are transferred at least over one membrane. Seventeen monoheme Cytc were predicted in species with either none (Haloferax spp., Halogeometricum borinquense, Halosarcina pallida, cluster 50) or only one maturation protein (Methanocella spp. Pyrobaculum arsenaticum) encoded in the genomes (Figure 2).

\section{Cytochromes c in Ignicoccus Hospitalis}

We had previously reported on the purification of three multiheme cytochromes $c$ (MCC) from the hyperthermophilic archaeon I. hospitalis (Naß et al., 2014). We had also reported that one of those cytochromes was a membrane-bound MCC with four CxxCH motifs (locus tag Igni_0530) and that two octaheme MCCs were present both in the soluble and the membrane fractions (Igni_1359 and Igni_0955). We had further predicted an octaheme tetrathionate reductase-like protein (Igni_1130) and two so far hypothetical monoheme cytochromes $c$ in the I. hospitalis proteome (Igni_0579 and Igni_1052; cluster 38). Here, we wanted to investigate in more detail whether the structure prediction used in Cytc identification in Archaea could substantiate this claim. We also extended structure prediction to the MCCs, again with the scope of extending the method more generally.

Igni_0579 and Igni_1052 are similar; Igni_1052 however has a second predicted $\mathrm{TMH}$ at its C-terminus not present in Igni_0759. Homologs occur in the related crenarchaeota Pyrolobus fumarii and Hyperthermus butylicus, both with a Cterminal TMH. The modeling servers (Phyre ${ }^{2}$ and I-Tasser) both used eukaryal spondin as the folding template (a nonheme protein, Tan et al., 2008) with high statistical confidence $(100 \%)$. The models left a cleft in the molecule sufficient for heme accommodation with the cysteine side chains positioned at the top of the cleft (Figure 4), thus pointing to a space where the heme might be positioned. In further modeling steps, the heme moiety was added to the Igni_0759 model PDB coordinate file and connected to the side chains of $\mathrm{Cys}_{28}$ and $\mathrm{Cys}_{31}$. After energy minimization, the iron atom was connected to $\mathrm{His}_{32}$ as proximal ligand and the protein was again subjected to energy minimization resulting in the model depicted in Figure 4. A further step connecting the iron to the side chain of $\mathrm{Cys}_{77}$ as putative distal ligand failed. His ${ }_{111}$ is a second candidate for the distal ligand and it is conserved in the homologs (cluster38_Igni_0759.fasta in the Archaea_Cytc.zip file). It was located beneath the $\beta$-sandwich forming the main structural body of the model so that we cannot presently decide, which of these two is correct. In summary, the model is congruent with the hypothesis that these I. hospitalis proteins are Cytc and they show that $3 \mathrm{D}$ structure prediction could be a valuable tool for the identification of unknown proteins, at least when applied to suspected monoheme Cytc.

Structure prediction was more difficult for the MCCs although Igni_1359 and Igni_0955 gave high-confidence (100\%) fulllength models with the Nitrosomonas europeae HAO 3D structure as template (PDB accession 1FGJ) with up to $28 \%$ sequence identity (not shown). Likewise, Igni_1130 gave a wellpredicted model with the Shewanella oneidensis OTR (3SP3; not shown). However, significant 3D models were also created when the three proteins were modeled with non-homologous MCC templates (e.g., Igni_1130 with the HAO template) regardless of sequence similarity. The MCCs seem to be folded into multiple pre-existing 3D structures because high numbers of hemebinding sites predefine the folding of the apoproteins, thereby 
restricting the predictive capabilities of structure modeling of MCCs. In consequence, a function prediction of MCC is at best difficult when trying to model non-homologous MCCs of unknown function, while monoheme Cytc give more reliable results.

\section{Discussion}

We present here a study for the identification of Cytc and their maturation proteins encoded in archaeal genomes using a computational approach coupled to an extensive manual evaluation of the results. We show that Cytc are not a common property of the majority of Archaea to our current knowledge and that they are not distributed equally, being restricted to 5-6 of the major taxa (Figure 3). In most Bacteria, Cytc are bound to cytoplasmic membranes or located in the periplasm or-in Gram-positives-in the space containing peptidoglycan and teichoic acids outside the cytoplasmic membrane, which is discussed to be equivalent to the periplasm of Gramnegatives (Matias and Beveridge, 2005). This is different in the compartmentalized Bacteria and Archaea. In the following discussion we will focus on two main questions:

1. What can we learn from the results of our computational study and the present state of knowledge about the distribution of Cytc, physiological patterns, and pathways in different archaeal lineages and about the acquisition of the genes during evolution?

2. What can we learn and predict about the localization and maturation of Cytc in Archaea and especially in doublemembraned microorganisms like I. hospitalis?

\section{Cytochromes $\mathrm{c}$ in Archaea}

Forty-seven archaeal species or consortia of uncultured microorganisms were found encoding both Cytc and CCM maturation proteins in their genomes while 17 other species harbor hypothetical single Cytc candidates with little evidence for maturation proteins (Table 1, Figure 2). They belong to only five different orders of Archaea with the exception of two proteins from a single-cell genome of a Thermoplasmatales species. Some of the archaeal Cytc have numerous homologs in Bacteria (e.g., clusters 3 and 4) while others are specific for Archaea (e.g., cluster 1-2).

There are differences in the distribution within Cytccontaining archaeal orders and even within single genera: The Archaeoglobales are the only order, in which all species sequenced so far contain Cytc genes (Figures 2, 3). In contrast, out of 17 genome-sequenced Thermoproteales species only Thermoproteus uzoniensis and 4-5 of 7 Pyrobaculum spp. contain Cytc genes (Figure 2, Table S1). For example, Pyrobaculum sp. strain 1860 and $P b$. oguniense grow by iron and nitrate respiration (Nunoura et al., 2003; Mardanov et al., 2012) and contain several monoheme Cytc and MCCs obviously involved in various electron transport chains. Two heme-stained proteins were observed in gel electrophoresis of cell extracts of Pyrobaculum aerophilum (Feinberg et al., 2008). The authors proposed that they are identical to Cytc subunits of a three-subunit $b c_{1}$ complex
(PAE1347-9) and of a two-subunit NirS-type $c d_{1}$ nitrite reductase (PAE3598). We also found both proteins in this study although the apparent molecular mass of the nitrate-induced band did not match the calculated mass of PAE3598 $(20 \mathrm{kDa}$ w/o signal peptide). Protein identification was not given so that ORF numbers of the two heme-stained proteins remain tentative.

The only biochemically purified three-subunit crenarchaeal $b c$ complex came from the microaerophilic species $A$. pernix (Kabashima and Sakamoto, 2011). In contrast, cyt $b c$ complexes are absent in aerobic Sulfolobales, which have an analogous cytochrome ba electron transport complex instead (Bandeiras et al., 2009). The Cytc subunit was the only one to be identified (Ape_1719.1). The adjacent gene encodes a subunit of a terminal oxidase, whereas the genes for cytochrome $b$ and a Rieske protein are close by but not in the same predicted operon (APE_1724.1 and APE_1725.1). Homologs of Ape_1719.1 are present in Pyrolobus fumarii and Hyperthermus butylicus but none of the cytochrome $b$ and the Rieske proteins. It can be concluded that Pyrobaculum spp., Thermoproteus uzoniensis, and Aeropyrum spp. encode canonical $b c$ complexes, whereas the homologous Cytc plays a different role in Pyrolobus and Hyperthermus, it might be part of an unidentified electron transport complex. The distribution pattern is similar in the remaining archaeal orders with Cytc. Some species of the Methanosarcinales and Halobacteriales encode single or multiple Cytc and the corresponding $\mathrm{ccm}$ genes but not the majority of either of them.

\section{Cytochromes c, Anaerobic Respiration, and Ammonia Oxidation}

An exceptionally high number of Cytc was found in the euryarchaeota Ferroglobus placidus (Figure 2) and $\mathrm{Ca}$. "Methanoperedens nitroreducens." F. placidus (and also the crenarchaeote Pyrolobus fumarii) grow by $\mathrm{Fe}^{2+}$ oxidation with nitrate or $\mathrm{Fe}^{3+}$ reduction with various organic and inorganic electron donors, whereas $\mathrm{Ca}$. "Mp. nitroreducens" grows by anaerobic oxidation of methane with nitrate (Hafenbradl et al., 1996; Anderson et al., 2011; Haroon et al., 2013). Several ANME Archaea however couple anaerobic methane oxidation to iron or manganese reduction (Beal et al., 2009; Wankel et al., 2012) and the diversity of Cytc in these Archaea was noted in the respective metagenome papers (Meyerdierks et al., 2010; Wang et al., 2014). Some of the large multiheme and multidomain proteins from F. placidus and Ca. "Mp. nitroreducens" (clusters 17 and 65) have 5-8 $\mathrm{CxxCH}$ motifs in their $\mathrm{N}$ - or C-terminal Cytc domains. Modeling the none-Cytc domains separately, those parts can be folded into chains of successive beta sandwich domains comparable to surface layer proteins (not shown). The results suggest that these proteins might form extracellular conductive structures or pili as in Shewanella or Geobacter. Here, periplasmic, outer-membrane, or pilus-bound Cytc transfer electrons to and from the cells (reviewed for example in Gorby et al., 2006; Richter et al., 2012; Boesen and Nielsen, 2013; Smith et al., 2015). This might provide a structural and biochemical basis of the metal ion-reducing and the presumed electronconductive capabilities of the iron-metabolizing Archaea. In a recent study, many heme-stained bands were found SDS gels 
of extracts of $\mathrm{Fe}^{3+}$-grown F. placidus cells. The number of bands and of transcripts of Cytc genes differed depending on the solution state of the iron: there were more Cytc proteins and corresponding transcripts in cells grown on solid compared to soluble $\mathrm{Fe}^{3+}$ species; in addition there were numerous type IV pili suggesting close attachment of the cells to the substrate and/or electrically conductive pili (Smith et al., 2015). By analogy, the sulfate reducer Archaeoglobus veneficus with a total of 16 Cytc genes should also be able to grow by metal respiration (Figure 2). In summary, metal ion respiration seems to be a predominant motif for the presence of high numbers of Cytc genes in archaeal genomes.

Bacterial sulfate reducers are typical sources of a large variety of Cytc (reviewed for example in Romão et al., 2012) and this seems also true for the Archaeoglobi but not for sulfatereducing crenarchaeota (e.g., Caldivirga maquilensis), since we did not find any Cytc genes in the latter microorganisms. Besides sulfate respiration, Cytc play important roles in oxidative and reductive pathways of microbial sulfur and nitrogen cycles such as denitrification, nitrate ammonification, thiosulfate oxidation, and anaerobic ammonium oxidation (Anammox; Kartal et al., 2011; Simon et al., 2011; Kappler and Maher, 2013; van Teeseling et al., 2013). Surprisingly, no Cytc were found in Thaumarchaeota, which represent a large phylum of Archaea characterized by their involvement in the global $\mathrm{N}$ cycle. Thaumarchaeota are proposed to be among the most abundant ammonia oxidizers in marine and in terrestrial ecosystems (Offre et al., 2013; Monteiro et al., 2014; Stieglmeier et al., 2014) and they might be implicated in denitrification as well (Jung et al., 2014). It is therefore surprising that the Thaumarchaeota seem to be (so far) devoid of Cytc suggesting that other proteins with comparable activities fill in the gap and that they use different catalytic metal sites.

\section{Methanogenesis}

Other Methanosarcinales species beside the ANME group contain Cytc as it was already discovered in the 1980s (Kuhn et al., 1983; Jussofie and Gottschalk, 1986). Two different Cytc were found spectroscopically in membrane fractions of methanol-grown Methanosarcina mazei Gö1 cells but the proteins were not purified or identified (Kamlage and Blaut, 1992). We found three monoheme and one multiheme Cytc gene in the Ms. mazei Gö1 genome (Table S1) but their assignment to the proteins reported by Kamlage and Blaut (1992) is currently not possible. Similarly, a multiheme Cytc was found to participate in electron transport of Ms. thermophila (Wang et al., 2011). In both cases, the Cytc were oxidized upon heterodisulfide addition (CoM-S-S-CoB) to membrane fractions however their precise role in the redox chains is not known. Methanosarcinales species are characterized by their utilization of various $C_{1}$ compounds and many can disproportionate acetate for methanogenesis and energy conservation. Now, Methanosarcinales are the only phylogenetic branch of methanogenic euryarchaeota (among at least six others) with both $b$ and $c$-type cytochromes but their presence does not seem to be a prerequisite for growth on these substrates. Chemiosmotic coupling during methanogenesis from $\mathrm{H}_{2} / \mathrm{CO}_{2}$ is the most probable reason for the observed higher growth yields in methanogens with cytochromes like Methanosarcina barkeri compared to those without (Thauer et al., 2008; Wang et al., 2011). The heterodisulfide reductase from Ms. barkeri contains a cytochrome $b$ subunit (Heiden et al., 1994; Kunkel et al., 1997). We did not find cytochromes $c$ in Ms. barkeri in our study here so that the cytochrome $b$ subunit alone seems to be responsible for the growth yield effect and there is no other indication that Cytc are integral players in this process. Generally, we observed here that only a small fraction of the known Methanosarcinales species contains Cytc suggesting a different role for these proteins in energy metabolism.

\section{The Haloarchaea Paradox}

Electron transport components from halophilic Archaea (Halobacteriales) were studied since the 1960s (Lanyi, 1968; Cheah, 1970). Later, Scharf et al. (1997) characterized a membrane-bound 2-subunit $b c$ complex (14 and $18 \mathrm{kDa}$, respectively) and a soluble $75 \mathrm{kDa}$ Cytc. A single Cytc candidate was identified in our computational analysis: a 453 aa cytochrome $c_{551}$ peroxidase (MauG, cluster 29) is encoded in the genome together with $\mathrm{ccm}$ genes as in several other haloarchaea and Methanosarcina species (Tables S1, S2). This could explain the $75-\mathrm{kDa}$ soluble heme-stained protein (Scharf et al., 1997). In contrast, we could not identify candidates for the heme-c protein of the $b c$ complex. The situation was similar for Halobacterium salinarum and Haloferax volcanii. In both species, Cytc were either purified ( $14 \mathrm{kDa}$ protein in Hbt. salinarum), and/or spectroscopically characterized combined with heme-stained SDS gels (Sreeramulu et al., 1998; Tanaka et al., 2002; Sreeramulu, 2003). Two small proteins were found encoded in the $H f x$. volcanii genome with little mutual sequence similarity and each with homologs in the same 12-13 haloarchaeal species (cluster 35 and 36; Figure 2) not including Hbt. salinarum. None of these species contain CCM. Both clusters gave low-confidence structure prediction hits (Table S2) so that independent evidence would be necessary for the identification of the Cytc component of the haloarchaeal $b c$ complexes. This leads to the conclusion that they might not be found using similarity and/or pattern searches and that they use non-standard amino acid patterns and heme $c$ linkage.

There were several other haloarchaeal species with wellrecognized and correctly annotated Cytc and $\mathrm{ccm}$ genes; cluster 28 comprising 368-485 aa proteins with a monoheme domain and the already mentioned cluster 29 (MauG-type peroxidases). The observation that some haloarchaea contain genes for cluster 28 and 29 Cytc only-the latter occurring in some of the Methanosarcinales as well-and the lack of MCCs suggests late gene acquisition from bacterial sources by horizontal gene transfer (HGT) as suggested earlier (Nelson-Sathi et al., 2012). A similar mechanism can be concluded for the metal-metabolizing archaeal species and the Methanosarcinales. In conclusion, the overall pattern suggests several events of horizontal transfer from Bacteria to Archaea as proposed as a general model of archaeal gene acquisition (Nelson-Sathi et al., 2015). In addition, the occurrence of Cytc genes seems to match physiological constraints rather than phylogenetic relationship. 


\section{Cytochromes $\mathrm{c}$ and Cell Morphology}

The majority of Archaea with cytochromes c-predicted in this study or biochemically proven-display the "standard" archaeal cell architecture: a cytoplasmic membrane covered with a proteinaceous surface (S-) layer anchored in the membrane (König et al., 2007). S-layers are protein canopies anchored in the cytoplasmic membrane encompassing a "quasi-" or "pseudoperiplasmic space” (Baumeister and Lembcke, 1992; König et al., 2007; Klingl, 2014), which can accommodate membrane-bound and soluble proteins (Baumeister et al., 1989; Veith et al., 2009; Protze et al., 2011; Klingl, 2014). It is therefore to be expected that Cytc are located in this space between cytoplasmic membrane and protein canopy and that they are retained either by pores in the protein lattice or by C-terminal membrane anchors as seen in many of the Cytc candidates described here (Table S1). Similarly, maturation of Cytc should also take place in this environment.

With their two membranes and the lack of an S-layer, Ignicoccus species are an exception to the typical archaeal cell architecture (Figures 1, 5). For Cytc, this encompasses the localization of the proteins, the location of the CCM machinery and last but not least the pathways of electron transport from the OCM to the inner compartment. Similar questions arise for the growing number of known double-membraned Archaea including the tiny Parvarchaeota of the ARMAN group (Comolli et al., 2009), the Methanoplasmatales (methanogens of the Thermoplasmata phylum; Dridi et al., 2012; Paul et al., 2012) and the uncultured SM1 euryarchaeota from a newly defined order Candidatus "Altiarchaeales" (Figure 1; Probst et al., 2014a,c). The distribution of proteins between the compartments and electron transfer is also unknown in those species. Ignicoccus spp. however, are the only double-membraned Archaea with cytochrome $c$. Immuno-labeling had shown that the octaheme MCCs Igni_0955 and Igni_1359 are localized at both membranes (and eventually also at vesicles in the intermembrane compartment (IMC); Figure 5; Naß et al., 2014).

The organisms of the bacterial phylum Planctomycetes display ostensibly similar cell morphologies and the question is whether that is comparable to the double-membraned Archaea and whether we can make deductions for protein distribution and electron pathways from these bacteria. Planctomycetes species are known to have an inner and outer membrane encompassing a "paryphoplasm" in addition to a protein S-layer (Lindsay et al., 2001; van Teeseling et al., 2014). The paryphoplasm was defined as a structural description of "a unique, peripheral ribosome-free region of cytoplasm" in order to distinguish it from the "riboplasm," the central compartment containing ribosomes and the nucleoid surrounded by an IM (Lindsay et al., 2001). There is also an ongoing discussion whether or not their membrane organization "is not different from, but an extension of, the "classical" Gram-negative bacterial membrane system" (Santarella-Mellwig et al., 2013; Sagulenko et al., 2014; Jeske et al., in press; van Teeseling et al., in press). Even more complex are Anammox bacteria like $\mathrm{Ca}$. "Kuenenia stuttgartiensis," also belonging to the Planctomycetes and also with an S-layer (Figure 5; van Teeseling et al., 2014). The cells have an additional cellular compartment, the anammoxosome within the riboplasm, which contains the proteins required for anaerobic ammonium oxidation including numerous cytochromes $c$ like hydroxylamine and hydrazine oxidoreductases. This compartment is the place of energy conversion; the anammoxosome membrane comprises a ph gradient across its ATP synthase-containing membrane with the positive (p) side inside (van Niftrik et al., 2008a, 2010; van der Star et al., 2010; Neumann et al., 2014). Therefore, it is reasonable to assume that maturation of the Cytc (using the system II) takes place in the anammoxosome and that the apoproteins are transported inside. The localization of Cytc is unknown in non-Anammox planctomycetes.

I. hospitalis differs in several aspects from the planctomycetes: it does not have an S-layer or a morphologically defined nucleoid and of course nothing equivalent to the anammoxosome. Also, the IMC is very lightly contrasted in electron microscopy pictures suggesting a low concentration of biomolecules. The same seems to be true for the Methanoplasmatales (Figure 1; Dridi et al., 2012). In contrast, the paryphoplasm of the planctomycetes usually is much darker in electron microscopy ("electron-dense") than the IMC (Figure 5; Lindsay et al., 2001). And third, the $I$. hospitalis ATP synthase and a heterologous hydrogenase/sulfur reductase complex are localized in the OCM (Küper et al., 2010). From this, we have to assume that the P-side is outside of the OCM. Maturation of the Cytc at the OCM however would require a transfer of the apoprotein and the heme moiety across two membrane systems (Figure 5). The latter cannot be excluded, however the mature Cytc would have to go back in to reach the IM, where they were found as well (Figure 5). A more easy explanation would be to assume that the apoprotein is transferred co-translationally across the IM via the sec pathway and that maturation would occur prior to further transport. This conclusion however would imply that the maturation takes place in the IMC but at the negative side of the cytoplasmic membrane unless there is an additional proton gradient across the IM. None of that is at present resolved (Huber et al., 2012).

A different question is about the function of the Cytc in I. hospitalis. We have proposed that the membrane-bound tetraheme Cytc Igni_0530 might be part of the sulfur reductase, however this is still hypothetical (Naß et al., 2014). Likewise hypothetical is the hypothesis that the Cytc might act as electron relay from the OCM-bound hydrogenase to oxidoreductases in the cytoplasm. We had measured reduction of Igni_0955 (and to a lesser extent Igni_1359) by the native hydrogenase supporting this assumption but it will have to be confirmed independently. At present we would disregard ferredoxins as electron transfer proteins because there are no ferredoxins with twin arginine signal peptides encoded in the I. hospitalis genome, which would be required for membrane transport of iron-sulfur proteins. The same observation was made for ferredoxins of $\mathrm{Ca}$. "K. stuttgartiensis," which lead to the-tentative-placement of the ferredoxins in the inner compartment or in the riboplasm, respectively, in the schematic drawings of Figure 5. We also did not find quinones by solvent extraction ( $\mathrm{Naß}$ et al., 2014). Therefore, the abundantly available Cytc are good candidates for electron transfer from the OCM to the inner compartment in $I$. hospitalis. 

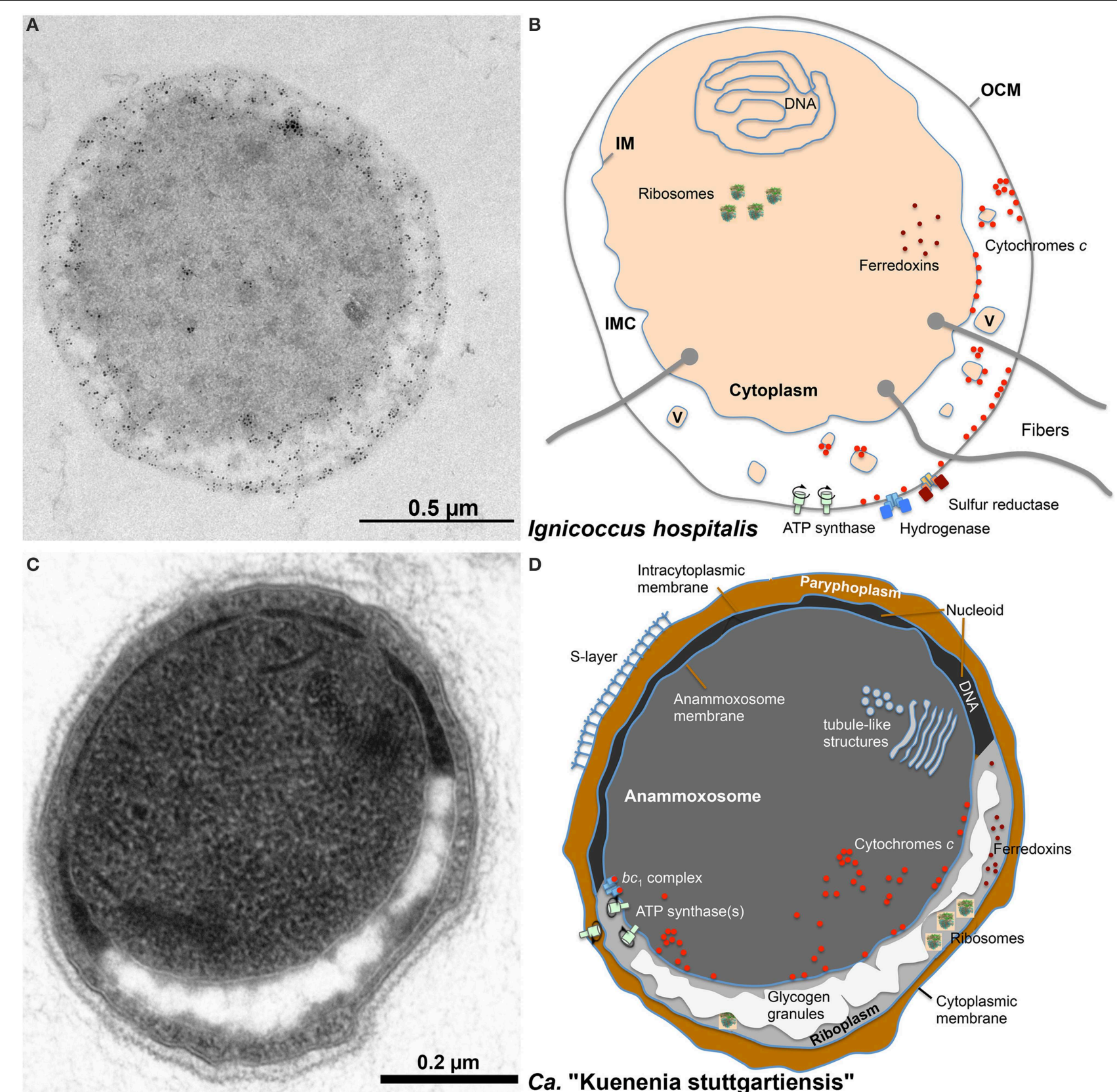

D

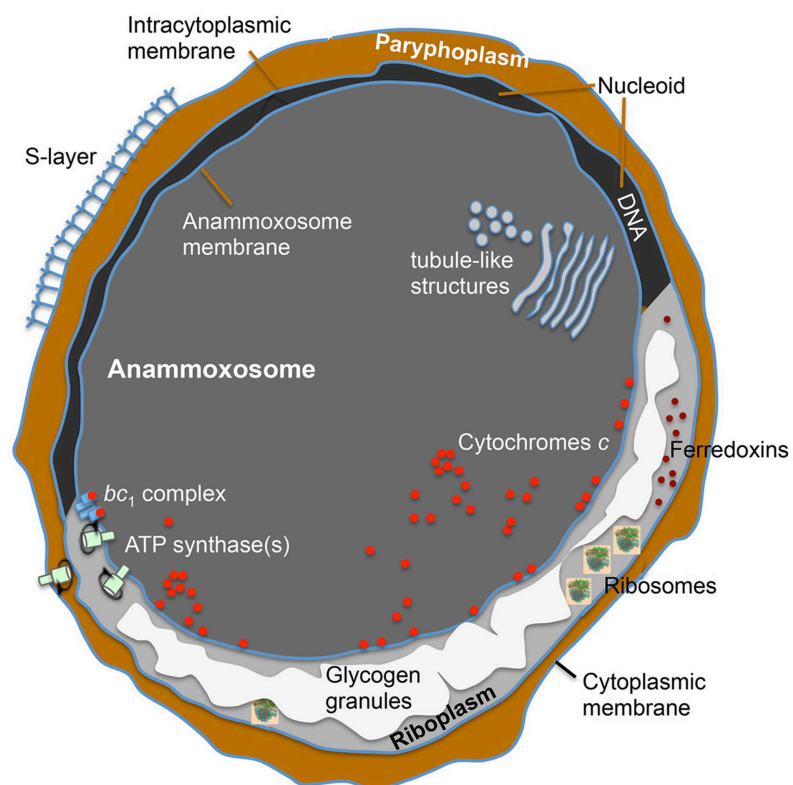

\section{Ca. "Kuenenia stuttgartiensis"}

FIGURE 5 | Comparison of the localization of cytochromes $c$ and other important proteins in I. hospitalis and in the Anammox bacterium Candidatus "Kuenenia stuttgartiensis." (A)

Immuno-labeling of an I. hospitalis ultrathin section with $\alpha$-Igni_0955 and gold-labeled $\alpha$-lgG secondary antibody; (B) schematic view of an I. hospitalis cell with ultrastructural features and known or predicted

distribution of proteins/enzymes; (C) ultrathin section of Ca. "K. stuttgartiensis"; (D) schematic view of a Ca. "K. stuttgartiensis" cell as above. OCM, outer cellular membrane; IMC, intermembrane compartment; IM, inner membrane; $\mathrm{V}$, vesicles; for the tubule-like structures in the anammoxosome of unknown function see van Niftrik et al. (2008b).

We can conclude about the comparison of I. hospitalis to the Anammox planctomycetales that the annamoxosomes of those bacteria are distinctly different structures and that the pathways of electron flow and the localization of Cytc is fundamentally different. Unfortunately, we do not know the localization of the respiratory chain(s) in the non-anammox planctomycetes, but they seem to be a system better comparable to the situation in
I. hospitalis especially regarding Cytc distribution and electron flow.

\section{Acknowledgments}

We thank Alexandra Perras and Christine Moissl-Eichinger (Medical University of Graz, Graz, Austria) for the samples 
for preparing the EM picture of Candidatus "Altiarchaeum hamiconexum" (Figure 1). TH, JF, and RR were supported by the Deutsche Forschungsgemeinschaft (DFG HU703/2-2). Special thanks are due to Felicitas Pfeifer (Darmstadt) for continuous support and discussion.

\section{Supplementary Material}

The Supplementary Material for this article can be found online at: http://journal.frontiersin.org/article/10.3389/fmicb. 2015.00439/abstract

\section{References}

Allen, J. W. (2011). Cytochrome $c$ biogenesis in mitochondria-Systems III and V. FEBS J. 278, 4198-4216. doi: 10.1111/j.1742-4658.2011.08231.x

Allen, J. W., Harvat, E. M., Stevens, J. M., and Ferguson, S. J. (2006). A variant System I for cytochrome $c$ biogenesis in Archaea and some Bacteria has a novel CcmE and no CcmH. FEBS Lett. 580, 4827-4834. doi: 10.1016/j.febslet.2006.07.073

Anderson, I., Risso, C., Holmes, D., Lucas, S., Copeland, A., Lapidus, A., et al. (2011). Complete genome sequence of Ferroglobus placidus AEDII12DO. Stand. Genomic Sci. 5, 50-60. doi: 10.4056/sigs.2225018

Bandeiras, T. M., Refojo, P. N., Todorovic, S., Murgida, D. H., Hildebrandt, P., Bauer, C., et al. (2009). The cytochrome $b a$ complex from the thermoacidophilic crenarchaeote Acidianus ambivalens is an analog of $b c(1)$ complexes. Biochim. Biophys. Acta 1787, 37-45. doi: 10.1016/j.bbabio.2008.09.009

Baumeister, W., and Lembcke, G. (1992). Structural features of archaebacterial cell envelopes. J. Bioenerg. Biomembr. 24, 567-575. doi: 10.1007/BF00762349

Baumeister, W., Wildhaber, W., and Phipps, B. M. (1989). Principles of organization in eubacterial and archaebacterial surface proteins. Can. J. Microbiol. 35, 215-227. doi: 10.1139/m89-034

Beal, E. J., House, C. H., and Orphan, V. J. (2009). Manganese- and iron-dependent marine methane oxidation. Science 325, 184-187. doi: 10.1126/science.1169984

Bendtsen, J. D., Nielsen, H., Widdick, D., Palmer, T., and Brunak, S. (2005). Prediction of twin-arginine signal peptides. BMC Bioinformatics 6:167. doi: 10.1186/1471-2105-6-167

Bertini, I., Cavallaro, G., and Rosato, A. (2006). Cytochrome $c$ : occurrence and functions. Chem. Rev. 106, 90-115. doi: 10.1021/cr050241v

Boesen, T., and Nielsen, L. P. (2013). Molecular dissection of bacterial nanowires. MBio 4, e00270-e00213. doi: 10.1128/mBio.00270-13

Burghardt, T., Nather, D. J., Junglas, B., Huber, H., and Rachel, R. (2007). The dominating outer membrane protein of the hyperthermophilic Archaeum Ignicoccus hospitalis: a novel pore-forming complex. Mol. Microbiol. 63, 166-176. doi: 10.1111/j.1365-2958.2006.05509.x

Cheah, K. S. (1970). Properties of the membrane-bound respiratory chain system of Halobacterium salinarium. Biochim. Biophys. Acta 216, 43-53. doi: 10.1016/0005-2728(70)90157-X

Comolli, L. R., Baker, B. J., Downing, K. H., Siegerist, C. E., and Banfield, J. F. (2009). Three-dimensional analysis of the structure and ecology of a novel, ultra-small archaeon. ISME J. 3, 159-167. doi: 10.1038/ismej.2008.99

Delano, W. L. (2002). The PyMOL Molecular Graphics System. San Carlos, CA: DeLano Scientific.

de Vitry, C. (2011). Cytochrome $c$ maturation system on the negative side of bioenergetic membranes: CCB or system IV. FEBS J. 278, 4189-4197. doi: 10.1111/j.1742-4658.2011.08373.x

Dirmeier, R., Keller, M., Frey, G., Huber, H., and Stetter, K. O. (1998). Purification and properties of an extremely thermostable membrane-bound sulfur-reducing complex from the hyperthermophilic Pyrodictium abyssi. Eur. J. Biochem. 252, 486-491. doi: 10.1046/j.1432-1327.1998.2520486.x

Dridi, B., Fardeau, M. L., Ollivier, B., Raoult, D., and Drancourt, M. (2012). Methanomassiliicoccus luminyensis gen. nov., sp. nov., a methanogenic archaeon isolated from human faeces. Int. J. Syst. Evol. Microbiol. 62, 1902-1907. doi: 10.1099/ijs.0.033712-0
Table S1 | Kletzin_cytochromes_Archaea_Table_S1.xlsx. Microsoft Excel file with complete dataset of all archaeal $\mathrm{CxxCH}$ motif-containing proteins identified in this study.

Table S2 | Kletzin_cytochromes_Archaea_Table_S2.xIsx. Microsoft Excel file with summary of sequence clusters with their respective structure prediction results and added remarks.

Igni_0759_pdb.zip | Zipped PDB coordinates of teh Igni_0759 3D model.

Archaea_Cytc.zip | Compressed file with the sequence clusters aligned in FASTA format. Cluster 17 is provided in 2 separate files: file "cluster17a.fasta" contains those cluster 17 proteins from Candidatus "Methanoperedens nitroreducens," which are characterized by a conserved C-terminus.

Feinberg, L. F., and Holden, J. F. (2006). Characterization of dissimilatory $\mathrm{Fe}(\mathrm{III})$ versus NO3- reduction in the hyperthermophilic archaeon Pyrobaculum aerophilum. J. Bacteriol. 188, 525-531. doi: 10.1128/JB.188.2.525-531.2006

Feinberg, L. F., Srikanth, R., Vachet, R. W., and Holden, J. F. (2008). Constraints on anaerobic respiration in the hyperthermophilic Archaea Pyrobaculum islandicum and Pyrobaculum aerophilum. Appl. Environ. Microbiol. 74, 396-402. doi: 10.1128/AEM.02033-07

Forterre, P. (2013). The common ancestor of archaea and eukarya was not an archaeon. Archaea 2013:372396. doi: 10.1155/2013/372396

Gorby, Y. A., Yanina, S., Mclean, J. S., Rosso, K. M., Moyles, D., Dohnalkova, A., et al. (2006). Electrically conductive bacterial nanowires produced by Shewanella oneidensis strain MR-1 and other microorganisms. Proc. Natl. Acad. Sci. U.S.A. 103, 11358-11363. doi: 10.1073/pnas. 0604517103

Guy, L., and Ettema, T. J. (2011). The archaeal 'TACK' superphylum and the origin of eukaryotes. Trends Microbiol. 19, 580-587. doi: 10.1016/j.tim.2011. 09.002

Hafenbradl, D., Keller, M., Dirmeier, R., Rachel, R., Rossnagel, P., Burggraf, S., et al. (1996). Ferroglobus placidus gen. nov., sp. nov., A novel hyperthermophilic archaeum that oxidizes $\mathrm{Fe}^{2+}$ at neutral $\mathrm{pH}$ under anoxic conditions. Arch. Microbiol. 166, 308-314. doi: 10.1007/s002030050388

Haroon, M. F., Hu, S., Shi, Y., Imelfort, M., Keller, J., Hugenholtz, P., et al. (2013). Anaerobic oxidation of methane coupled to nitrate reduction in a novel archaeal lineage. Nature 500, 567-570. doi: 10.1038/nature 12375

Heiden, S., Hedderich, R., Setzke, E., and Thauer, R. K. (1994). Purification of a two-subunit cytochrome- $b$-containing heterodisulfide reductase from methanol-grown Methanosarcina barkeri. Eur. J. Biochem. 221, 855-861. doi: 10.1111/j.1432-1033.1994.tb18800.x

Hirokawa, T., Boon-Chieng, S., and Mitaku, S. (1998). SOSUI: classification and secondary structure prediction system for membrane proteins. Bioinformatics 14, 378-379. doi: 10.1093/bioinformatics/14.4.378

Huber, H., Küper, U., Daxer, S., and Rachel, R. (2012). The unusual cell biology of the hyperthermophilic Crenarchaeon Ignicoccus hospitalis. Antonie Van Leeuwenhoek 102, 203-219. doi: 10.1007/s10482-012-9748-5

Jeske, O., Schuffler, M., Schumann, P., Schneider, A., Boedeker, C., Jogler, M., et al. (in press). Planctomycetes do possess a peptidoglycan cell wall. Nat. Comm.

Jung, M. Y., Well, R., Min, D., Giesemann, A., Park, S. J., Kim, J. G., et al. (2014). Isotopic signatures of $\mathrm{N} 2 \mathrm{O}$ produced by ammonia-oxidizing archaea from soils. ISME J. 8, 1115-1125. doi: 10.1038/ismej.2013.205

Jussofie, A., and Gottschalk, G. (1986). Further-studies on the distribution of cytochromes in Methanogenic bacteria. FEMS Microbiol. Lett. 37, 15-18. doi: $10.1111 / j .1574-6968.1986 . t b 01758 . x$

Kabashima, Y., and Sakamoto, J. (2011). Purification and biochemical properties of a cytochrome $b c$ complex from the aerobic hyperthermophilic archaeon Aeropyrum pernix. BMC Microbiol. 11:52. doi: 10.1186/1471-2180-11-52

Kamlage, B., and Blaut, M. (1992). Characterization of cytochromes from Methanosarcina strain Gö1 and their involvement in electron transport during growth on methanol. J. Bacteriol. 174, 3921-3927.

Kappler, U., and Maher, M. J. (2013). The bacterial SoxAX cytochromes. Cell. Mol. Life Sci. 70, 977-992. doi: 10.1007/s00018-012-1098-y

Kartal, B., Maalcke, W. J., de Almeida, N. M., Cirpus, I., Gloerich, J., Geerts, W., et al. (2011). Molecular mechanism of anaerobic ammonium oxidation. Nature 479, 127-130. doi: 10.1038/nature10453 
Katoh, K., and Standley, D. M. (2014). MAFFT: iterative refinement and additional methods. Methods Mol. Biol. 1079, 131-146. doi: 10.1007/978-1-62703-646-7_8

Kelley, L. A., and Sternberg, M. J. (2009). Protein structure prediction on the web: a case study using the Phyre server. Nat. Protoc. 4, 363-371. doi: $10.1038 /$ nprot.2009.2

Kern, M., Klotz, M. G., and Simon, J. (2011). The Wolinella succinogenes mcc gene cluster encodes an unconventional respiratory sulphite reduction system. Mol. Microbiol. 82, 1515-1530. doi: 10.1111/j.1365-2958.2011.07906.x

Klingl, A. (2014). S-layer and cytoplasmic membrane - exceptions from the typical archaeal cell wall with a focus on double membranes. Front. Microbiol. 5:624. doi: 10.3389/fmicb.2014.00624

König, H., Rachel, R., and Claus, H. (2007). "Proteinaceous surface layers of Archaea: ultrastructure and biochemistry," in Archaea. Molecular and Cellular Biology, ed R. Cavicchioli (Washington, DC: ASM Press), 315-340.

Krogh, A., Larsson, B., Von Heijne, G., and Sonnhammer, E. L. (2001). Predicting transmembrane protein topology with a hidden Markov model: application to complete genomes. J. Mol. Biol. 305, 567-580. doi: 10.1006/jmbi.2000.4315

Kuhn, W., Fiebig, K., Hippe, H., Mah, R. A., Huser, B. A., and Gottschalk, G. (1983). Distribution of cytochromes in Methanogenic bacteria. FEMS Microbiol. Lett. 20, 407-410. doi: 10.1016/0378-1097(83)90105-2

Kunkel, A., Vaupel, M., Heim, S., Thauer, R. K., and Hedderich, R. (1997). Heterodisulfide reductase from methanol-grown cells of Methanosarcina barkeri is not a flavoenzyme. Eur. J. Biochem. 244, 226-234. doi: 10.1111/j.14321033.1997.00226.x

Küper, U., Meyer, C., Müller, V., Rachel, R., and Huber, H. (2010). Energized outer membrane and spatial separation of metabolic processes in the hyperthermophilic Archaeon Ignicoccus hospitalis. Proc. Natl. Acad. Sci. U.S.A. 107, 3152-3156. doi: 10.1073/pnas.0911711107

Lanyi, J. K. (1968). Studies of the electron transport chain of extremely halophilic bacteria. I. Spectrophotometric identification of the cytochromes of Halobacterium cutirubrum. Arch. Biochem. Biophys. 128, 716-724. doi: 10.1016/0003-9861(68)90080-5

Lindsay, M. R., Webb, R. I., Strous, M., Jetten, M. S., Butler, M. K., Forde, R. J., et al. (2001). Cell compartmentalisation in planctomycetes: novel types of structural organisation for the bacterial cell. Arch. Microbiol. 175, 413-429. doi: $10.1007 / \mathrm{s} 002030100280$

Lockwood, C. W., Clarke, T. A., Butt, J. N., Hemmings, A. M., and Richardson, D. J. (2011). Characterization of the active site and calcium binding in cytochrome $c$ nitrite reductases. Biochem. Soc. Trans. 39, 1871-1875. doi: 10.1042/BST20110731

Mardanov, A. V., Gumerov, V. M., Slobodkina, G. B., Beletsky, A. V., BonchOsmolovskaya, E. A., Ravin, N. V., et al. (2012). Complete genome sequence of strain 1860, a crenarchaeon of the genus Pyrobaculum able to grow with various electron acceptors. J. Bacteriol. 194, 727-728. doi: 10.1128/JB. 06465-11

Matias, V. R., and Beveridge, T. J. (2005). Cryo-electron microscopy reveals native polymeric cell wall structure in Bacillus subtilis 168 and the existence of a periplasmic space. Mol. Microbiol. 56, 240-251. doi: 10.1111/j.13652958.2005.04535.x

Mayer, F., Küper, U., Meyer, C., Daxer, S., Müller, V., Rachel, R., et al. (2012). AMP-forming acetyl coenzyme A synthetase in the outermost membrane of the hyperthermophilic crenarchaeon Ignicoccus hospitalis. J. Bacteriol. 194, 1572-1581. doi: 10.1128/JB.06130-11

Mayer, F., and Müller, V. (2014). Adaptations of anaerobic archaea to life under extreme energy limitation. FEMS Microbiol. Rev. 38, 449-472. doi: 10.1111/1574-6976.12043

Meyer, C., Heimerl, T., Wirth, R., Klingl, A., and Rachel, R. (2014). The Iho670 fibers of Ignicoccus hospitalis are anchored in the cell by a spherical structure located beneath the inner membrane. J. Bacteriol. 196, 3807-3815. doi: 10.1128/JB.01861-14

Meyerdierks, A., Kube, M., Kostadinov, I., Teeling, H., Glockner, F. O., Reinhardt, R., et al. (2010). Metagenome and mRNA expression analyses of anaerobic methanotrophic archaea of the ANME-1 group. Environ. Microbiol. 12, 422-439. doi: 10.1111/j.1462-2920.2009.02083.x

Moissl, C., Rachel, R., Briegel, A., Engelhardt, H., and Huber, R. (2005). The unique structure of archaeal 'hami', highly complex cell appendages with nano-grappling hooks. Mol. Microbiol. 56, 361-370. doi: 10.1111/j.13652958.2005.04294.x
Monteiro, M., Seneca, J., and Magalhaes, C. (2014). The history of aerobic ammonia oxidizers: from the first discoveries to today. J. Microbiol. 52, 537-547. doi: 10.1007/s12275-014-4114-0

Mooser, D., Maneg, O., Macmillan, F., Malatesta, F., Soulimane, T., and Ludwig, B. (2006). The menaquinol-oxidizing cytochrome $b c$ complex from Thermus thermophilus: protein domains and subunits. Biochim. Biophys. Acta 1757, 1084-1095. doi: 10.1016/j.bbabio.2006.05.033

Naß, B., Pöll, U., Langer, J. D., Kreuter, L., Küper, U., Flechsler, J., et al. (2014). Three multihaem cytochromes $c$ from the hyperthermophilic archaeon Ignicoccus hospitalis: purification, properties and localization. Microbiology 160, 1278-1289. doi: 10.1099/mic.0.077792-0

Nelson-Sathi, S., Dagan, T., Landan, G., Janssen, A., Steel, M., Mcinerney, J. O., et al. (2012). Acquisition of 1000 eubacterial genes physiologically transformed a methanogen at the origin of Haloarchaea. Proc. Natl. Acad. Sci. U.S.A. 109, 20537-20542. doi: 10.1073/pnas.1209119109

Nelson-Sathi, S., Sousa, F. L., Roettger, M., Lozada-Chavez, N., Thiergart, T., Janssen, A., et al. (2015). Origins of major archaeal clades correspond to gene acquisitions from bacteria. Nature 517, 77-80. doi: 10.1038/nature 13805

Neumann, S., Wessels, H. J., Rijpstra, W. I., Sinninghe Damste, J. S., Kartal, B., Jetten, M. S., et al. (2014). Isolation and characterization of a prokaryotic cell organelle from the anammox bacterium Kuenenia stuttgartiensis. Mol. Microbiol. 94, 794-802. doi: 10.1111/mmi.12816

Noor, M. R., and Soulimane, T. (2013). Structure of caa(3) cytochrome $c$ oxidasea nature-made enzyme-substrate complex. Biol. Chem. 394, 579-591. doi: 10.1515/hsz-2012-0343

Nunoura, T., Sako, Y., Wakagi, T., and Uchida, A. (2003). Regulation of the aerobic respiratory chain in the facultatively aerobic and hyperthermophilic archaeon Pyrobaculum oguniense. Microbiology 149, 673-688. doi: 10.1099/mic.0. 26000-0

Offre, P., Spang, A., and Schleper, C. (2013). Archaea in biogeochemical cycles. Annu. Rev. Microbiol. 67, 437-457. doi: 10.1146/annurev-micro-092412155614

Paul, K., Nonoh, J. O., Mikulski, L., and Brune, A. (2012). "Methanoplasmatales," Thermoplasmatales-related archaea in termite guts and other environments, are the seventh order of methanogens. Appl. Environ. Microbiol. 78, 8245-8253. doi: 10.1128/AEM.02193-12

Perras, A. K., Wanner, G., Klingl, A., Mora, M., Auerbach, A. K., Heinz, V., et al. (2014). Grappling archaea: ultrastructural analyses of an uncultivated, cold-loving archaeon, and its biofilm. Front. Microbiol. 5:397. doi: 10.3389/fmicb.2014.00397

Petersen, T. N., Brunak, S., von Heijne, G., and Nielsen, H. (2011). SignalP 4.0: discriminating signal peptides from transmembrane regions. Nat. Methods 8, 785-786. doi: 10.1038/nmeth.1701

Petitjean, C., Deschamps, P., Lopez-Garcia, P., and Moreira, D. (2014). Rooting the domain archaea by phylogenomic analysis supports the foundation of the new kingdom Proteoarchaeota. Genome Biol. Evol. 7, 191-204. doi: 10.1093/gbe/evu274

Pettersen, E. F., Goddard, T. D., Huang, C. C., Couch, G. S., Greenblatt, D. M., Meng, E. C., et al. (2004). UCSF Chimera-a visualization system for exploratory research and analysis. J. Comput. Chem. 25, 1605-1612. doi: 10.1002/jcc. 20084

Pihl, T. D., Black, L. K., Schulman, B. A., and Maier, R. J. (1992). Hydrogen-oxidizing electron transport components in the hyperthermophilic archaebacterium Pyrodictium brockii. J. Bacteriol. 174, 137-143.

Probst, A. J., Birarda, G., Holman, H. Y., Desantis, T. Z., Wanner, G., Andersen, G. L., et al. (2014a). Coupling genetic and chemical microbiome profiling reveals heterogeneity of archaeome and bacteriome in subsurface biofilms that are dominated by the same archaeal species. PLoS ONE 9:e99801. doi: 10.1371/journal.pone.0099801

Probst, A. J., Weinmaier, T., Raymann, K., Perras, A., Emerson, J. B., Rattei, T., et al. (2014c). Biology of a widespread uncultivated archaeon that contributes to carbon fixation in the subsurface. Nat. Commun. 5, 5497. doi: $10.1038 /$ ncomms6497

Protze, J., Müller, F., Lauber, K., Nass, B., Mentele, R., Lottspeich, F., et al. (2011). An extracellular Tetrathionate Hydrolase from the Thermoacidophilic Archaeon Acidianus ambivalens with an activity optimum at $\mathrm{pH} 1$. Front. Microbiol. 2:68. doi: 10.3389/fmicb.2011.00068 
Rachel, R., Meyer, C., Klingl, A., Gurster, S., Heimerl, T., Wasserburger, N., et al. (2010). Analysis of the ultrastructure of archaea by electron microscopy. Methods Cell Biol. 96, 47-69. doi: 10.1016/S0091-679X(10)96003-2

Richter, K., Schicklberger, M., and Gescher, J. (2012). Dissimilatory reduction of extracellular electron acceptors in anaerobic respiration. Appl. Environ. Microbiol. 78, 913-921. doi: 10.1128/AEM.06803-11

Romão, C. V., Archer, M., Lobo, S. A., Louro, R. O., Pereira, I. A. C., Saraiva, L. M., et al., (2012). "Diversity of heme proteins in sulfate reducing bacteria," in Handbook of Porphyrin Science, eds K. M. Kadish, K. M. Smith, and R. Guilard (Singapore: World Scientific Publishing Co.), 139-229.

Roy, A., Kucukural, A., and Zhang, Y. (2010). I-TASSER: a unified platform for automated protein structure and function prediction. Nat. Protoc. 5, 725-738. doi: $10.1038 /$ nprot.2010.5

Sagulenko, E., Morgan, G. P., Webb, R. I., Yee, B., Lee, K. C., and Fuerst, J. A. (2014). Structural studies of planctomycete Gemmata obscuriglobus support cell compartmentalisation in a bacterium. PLOS ONE 9:e91344. doi: 10.1371/journal.pone.0091344

Santarella-Mellwig, R., Pruggnaller, S., Roos, N., Mattaj, I. W., and Devos, D. P. (2013). Three-dimensional reconstruction of bacteria with a complex endomembrane system. PLoS Biol. 11:e1001565. doi: 10.1371/journal.pbio. 1001565

Schäfer, G. (2004). "Respiratory chains in Archaea: from minimal systems to supercomplexes," in Respiration in Archaea and Bacteria. Diversity of Prokaryotic Respiratory Systems, ed D. Zannoni (Dordrecht: Springer), 1-33.

Schäfer, G., Engelhard, M., and Müller, V. (1999). Bioenergetics of the Archaea. Microbiol. Mol. Biol. Rev. 63, 570-620.

Scharf, B., Wittenberg, R., and Engelhard, M. (1997). Electron transfer proteins from the haloalkaliphilic archaeon Natronobacterium pharaonis: possible components of the respiratory chain include cytochrome $b c$ and a terminal oxidase cytochrome ba3. Biochemistry 36, 4471-4479. doi: 10.1021/ bi962312d

Seiler, M., Mehrle, A., Poustka, A., and Wiemann, S. (2006). The 3 of5 web application for complex and comprehensive pattern matching in protein sequences. BMC Bioinformatics 7:144. doi: 10.1186/1471-2105-7-144

Sharma, S., Cavallaro, G., and Rosato, A. (2010). A systematic investigation of multiheme c-type cytochromes in prokaryotes. J. Biol. Inorg. Chem. 15, 559-571. doi: 10.1007/s00775-010-0623-4

Simon, J., and Hederstedt, L. (2011). Composition and function of cytochrome c biogenesis System II. FEBS J. 278, 4179-4188. doi: 10.1111/j.17424658.2011.08374.x

Simon, J., Kern, M., Hermann, B., Einsle, O., and Butt, J. N. (2011). Physiological function and catalytic versatility of bacterial multihaem cytochromes $c$ involved in nitrogen and sulfur cycling. Biochem. Soc. Trans. 39, 1864-1870. doi: 10.1042/BST20110713

Smith, J., Aklujkar, M., Risso, C., Leang, C., Giloteaux, L., and Holmes, D. (2015). Mechanisms involved in $\mathrm{Fe}(\mathrm{III})$ respiration by the hyperthermophilic archaeon Ferroglobus placidus. Appl. Environ. Microbiol. 81, 2735-2744. doi: 10.1128/AEM.04038-14

Sreeramulu, K. (2003). Purification and partial characterization of a cytochrome $c_{552}$ from Halobacterium salinarum. Ind. J. Biochem. Biophys. 40, 274-277.

Sreeramulu, K., Schmidt, C. L., Schäfer, G., and Anemüller, S. (1998). Studies of the electron transport chain of the euryarcheon Halobacterium salinarum: indications for a type II NADH dehydrogenase and a complex III analog. J. Bioenerg. Biomembr. 30, 443-453. doi: 10.1023/A:10205381 29400

Stevens, J. M., Mavridou, D. A., Hamer, R., Kritsiligkou, P., Goddard, A. D., and Ferguson, S. J. (2011). Cytochrome c biogenesis system I. FEBS J. 278, 4170-4178. doi: 10.1111/j.1742-4658.2011.08376.x

Stieglmeier, M., Klingl, A., Alves, R. J., Rittmann, S. K., Melcher, M., Leisch, N., et al. (2014). Nitrososphaera viennensis gen. nov., sp. nov., an aerobic and mesophilic, ammonia-oxidizing archaeon from soil and a member of the archaeal phylum Thaumarchaeota. Int. J. Syst. Evol. Microbiol. 64, 2738-2752. doi: 10.1099/ijs.0.063172-0

Tan, K., Duquette, M., Liu, J. H., Lawler, J., and Wang, J. H. (2008). The crystal structure of the heparin-binding reelin-N domain of f-spondin. J. Mol. Biol. 381, 1213-1223. doi: 10.1016/j.jmb.2008.06.045

Tanaka, M., Ogawa, N., Ihara, K., Sugiyama, Y., and Mukohata, Y. (2002). Cytochrome $a a(3)$ in Haloferax volcanii. J. Bacteriol. 184, 840-845. doi: 10.1128/JB.184.3.840-845.2002
Thauer, R. K., Kaster, A. K., Seedorf, H., Buckel, W., and Hedderich, R. (2008), Methanogenic archaea: ecologically relevant differences in energy conservation. Nat. Rev. Microbiol. 6, 579-591. doi: 10.1038/nrmicro1931

van der Star, W. R., Dijkema, C., de Waard, P., Picioreanu, C., Strous, M., and Van Loosdrecht, M. C. (2010). An intracellular pH gradient in the anammox bacterium Kuenenia stuttgartiensis as evaluated by 31P NMR. Appl. Microbiol. Biotechnol. 86, 311-317. doi: 10.1007/s00253-009-2309-9

van Niftrik, L., Geerts, W. J., van Donselaar, E. G., Humbel, B. M., Webb, R. I., Fuerst, J. A., et al. (2008a). Linking ultrastructure and function in four genera of anaerobic ammonium-oxidizing bacteria: cell plan, glycogen storage, and localization of cytochrome $c$ proteins. J. Bacteriol. 190, 708-717. doi: 10.1128/JB.01449-07

van Niftrik, L., Geerts, W. J., van Donselaar, E. G., Humbel, B. M., Yakushevska, A., Verkleij, A. J., et al. (2008b). Combined structural and chemical analysis of the anammoxosome: a membrane-bounded intracytoplasmic compartment in anammox bacteria. J. Struct. Biol. 161, 401-410. doi: 10.1016/j.jsb.2007. 05.005

van Niftrik, L., van Helden, M., Kirchen, S., van Donselaar, E. G., Harhangi, H. R., Webb, R. I., et al. (2010). Intracellular localization of membranebound ATPases in the compartmentalized anammox bacterium 'Candidatus Kuenenia stuttgartiensis'. Mol. Microbiol. 77, 701-715. doi: 10.1111/j.13652958.2010.07242.x

van Teeseling, M. C., de Almeida, N. M., Klingl, A., Speth, D. R., Op den Camp, H. J., Rachel, R., et al. (2014). A new addition to the cell plan of anammox bacteria: "Candidatus Kuenenia stuttgartiensis" has a protein surface layer as the outermost layer of the cell. J. Bacteriol. 196, 80-89. doi: 10.1128/JB. 00988-13

van Teeseling, M. C. F., Mesman, R. J., Kuru, E., Espaillat, A., Cava, F., Brun, Y. V., et al. (in press). Anammox Planctomycetes have a peptidoglycan cell wall. Nat. Comm.

van Teeseling, M. C., Neumann, S., and van Niftrik, L. (2013). The anammoxosome organelle is crucial for the energy metabolism of anaerobic ammonium oxidizing bacteria. J. Mol. Microbiol. Biotechnol. 23, 104-117. doi: $10.1159 / 000346547$

Veith, A., Klingl, A., Zolghadr, B., Lauber, K., Mentele, R., Lottspeich, F., et al. (2009). Acidianus, Sulfolobus and Metallosphaera surface layers: structure, composition and gene expression. Mol. Microbiol. 73, 58-72. doi: $10.1111 / j .1365-2958.2009 .06746 . x$

Verissimo, A. F., and Daldal, F. (2014). Cytochrome $c$ biogenesis system I: an intricate process catalyzed by a maturase supercomplex? Biochim. Biophys. Acta 1837, 989-998. doi: 10.1016/j.bbabio.2014.03.003

Wang, F. P., Zhang, Y., Chen, Y., He, Y., Qi, J., Hinrichs, K. U., et al. (2014). Methanotrophic archaea possessing diverging methane-oxidizing and electron-transporting pathways. ISME J. 8, 1069-1078. doi: 10.1038/ismej. 2013.212

Wang, M., Tomb, J. F., and Ferry, J. G. (2011). Electron transport in acetate-grown Methanosarcina acetivorans. BMC Microbiol. 11:165. doi: 10.1186/1471-218011-165

Wankel, S. D., Adams, M. M., Johnston, D. T., Hansel, C. M., Joye, S. B., and Girguis, P. R. (2012). Anaerobic methane oxidation in metalliferous hydrothermal sediments: influence on carbon flux and decoupling from sulfate reduction. Environ. Microbiol. 14, 2726-2740. doi: 10.1111/j.14622920.2012.02825.x

Wu, M. L., Van Teeseling, M. C., Willems, M. J., Van Donselaar, E. G., Klingl, A., Rachel, R., et al. (2012). Ultrastructure of the denitrifying methanotroph "Candidatus Methylomirabilis oxyfera," a novel polygon-shaped bacterium. J. Bacteriol. 194, 284-291. doi: 10.1128/JB.05816-11

Conflict of Interest Statement: The authors declare that the research was conducted in the absence of any commercial or financial relationships that could be construed as a potential conflict of interest.

Copyright $\odot 2015$ Kletzin, Heimerl, Flechsler, van Niftrik, Rachel and Klingl. This is an open-access article distributed under the terms of the Creative Commons Attribution License (CC BY). The use, distribution or reproduction in other forums is permitted, provided the original author(s) or licensor are credited and that the original publication in this journal is cited, in accordance with accepted academic practice. No use, distribution or reproduction is permitted which does not comply with these terms. 